Opportunity \&

Inclusive Growth

T]

M

FEDERAL RESERVE BANK OF MINNEAPOLIS

INSTITUTE WORKING PAPER

No. 47

\title{
Saving the American Dream? Education Policies in Spatial General Equilibrium
}

March 2021

\section{Fabian Eckert}

University of California, San Diego

\section{Tatjana Kleineberg}

World Bank

DOI: https://doi.org/10.21034/iwp.47

Keywords: Intergenerational mobility; Equality of opportunity; School access; Education reform; Regional labor markets; Economic geography; Spatial economics

JEL classification: E24, E62, R12, R23, R75, I24, I28

The views expressed herein are those of the authors and not necessarily those of the Federal Reserve Bank of Minneapolis or the Federal Reserve System. 


\title{
Saving the American Dream? \\ Education Policies in Spatial General Equilibrium*
}

\author{
Fabian Eckert ${ }^{\dagger} \quad$ Tatjana Kleineberg ${ }^{\ddagger}$
}

First Version: November 2017

This Version: March 2021

\begin{abstract}
Children's education and economic opportunities differ substantially across US neighborhoods. This paper develops and estimates a spatial equilibrium model that links children's education outcomes to their childhood location. Two endogenous factors determine education choices in each location: local education quality and local labor market access. We estimate the model with US county-level data and study the effects of a school funding equalization on education outcomes and social mobility. The reform's direct effects improve education outcomes among children from low-skill families. However, the effects are weaker in spatial general equilibrium because average returns to education decline and residential and educational choices of low-skill families shift them toward locations with lower education quality.
\end{abstract}

Keywords: Intergenerational Mobility, Equality of Opportunity, School Access, Education Reform, Regional Labor Markets, Economic Geography, Spatial Economics

JEL Codes: E24, E62, R12, R23,R75, I24, I28

\footnotetext{
*This article is a revised version of the first chapter of Kleineberg's PhD dissertation at Yale University, which circulated under the title "Can We Save the American Dream? A Dynamic General Equilibrium Analysis of the Effects of School Financing on Local Opportunities." We are indebted to Giuseppe Moscarini, Samuel Kortum, Michael Peters and Fabrizio Zilibotti for their continued and invaluable support and guidance in this project. In addition, we are very grateful to Joseph Altonji, Costas Arkolakis, Lorenzo Caliendo, Ellora Derenoncourt, Ed Glaeser, Nathan Hendren, Joachim Hubmer, Ilse Lindenlaub, Costas Meghir, Pascual Restrepo, Mark Rosenzweig, Tony Smith, Sharon Traiberman, Aleh Tsyvinski, and Conor Walsh for helpful discussions and suggestions. We are also grateful to audiences at Yale, Harvard, Princeton, NYU, NYU-Stern, IIES Stockholm, Philadelphia Fed, Wisconsin, the World Bank, as well as at the Penn State New Faces in International Economics Conference, the Yale Cowles Macro Conference 2019, the SED 2019, and the NBER Urban SI 2019. We owe special thanks to Rucker Johnson for providing additional estimation results. The findings, interpretations, and conclusions expressed in this paper are entirely those of the authors. They do not necessarily represent the views of the World Bank and its affiliated organizations, or those of the Executive Directors of the World Bank or the governments they represent.

${ }^{\dagger}$ Department of Economics; University of California, San Diego; Email: fpe@ucsd.edu

‡Development Research Group; World Bank; Email: tkleineberg@worldbank.org
} 


\section{INTRODUCTION}

Neighborhoods in the United States have an important impact on children's education and economic outcomes. Policies to increase social mobility and equality of opportunity could therefore try to improve disadvantaged locations, for example, through higher school funding, or incentivize families to move to better-performing locations, for example, through rent subsidies. However, the success of such policies depends on why certain locations produce better outcomes and whether that changes in response to policies.

Childhood neighborhoods matter for children's long-run outcomes for two reasons. First, the place where children grow up determines their future wages and returns to education because it is costly to move. Second, childhood neighborhoods differ in education environments, which depend on local schools and other neighborhood characteristics. We refer to these two channels as "local labor market access" and "local education quality." Importantly, both channels interact with each other and change in response to policies, for example, through adjustments in local prices or local skill compositions.

In this paper, we therefore develop a spatial equilibrium framework that accounts for these feedback effects by jointly modeling local labor markets, local education environments, and families' education and residential choices. We use our estimated model to evaluate an equalization of school funding and show that interactions in spatial equilibrium shape the long-run effects of the policy.

Seminal work that studies the link between residential choices, education outcomes, and intergenerational mobility dates back to the 1990s and was mostly theoretical (cf. Benabou (1993, 1996), Durlauf (1996a,b) and Fernandez and Rogerson (1996, 1997, 1998)). We use recent advances in spatial economics (cf. Redding and Rossi-Hansberg (2017)) to study these research questions by developing a quantitative spatial model with local education quality and local education choices. Chetty and Hendren (2018b) provide causal effects of childhood neighborhoods on children's education outcomes for the entire United States, which makes it possible to estimate our spatial model.

We begin by providing evidence that labor market access and education quality vary across US locations. We show that individuals are more likely to stay in or near the location in which they grow up and that wages and skill premia differ across locations. These facts together imply that returns to education differ across childhood locations. We further document that school funding-one important determinant of education qualityvaries substantially across locations.

We then develop a spatial equilibrium framework that formalizes these mechanisms. In- 
dividuals live for two periods: childhood and adulthood. Children choose to remain low-skill (high school) or to become high-skill (college), which is fixed during adulthood. Education choices depend on local education quality and local returns to education. After choosing their education, individuals may have children themselves and then choose their adulthood location. Parents' residential choices take the utility that destinations offer to their children into account. We call this utility destinations' "child opportunity values," which depend on local education quality and local labor market access. Child opportunity values vary by parental education because children from low- and high-skill parents may benefit differentially from local opportunities.

The model has a nested geography where larger "labor markets" nest smaller "neighborhoods." Labor market clearing determines local wages and skill premia. Children's future returns to education depend on their childhood locations because it is costly to move. Neighborhoods differ in education quality, rents, and amenities. The model has a dynastic structure in which each time period represents one generation. Residential and education choices jointly determine how the distribution of workers across skills and locations evolves over generations. Local labor market access and local education quality depend on the distribution of workers, making all of these objects equilibrium outcomes. Our model can be used to study many research and policy questions. We focus on school funding reforms and parameterize locations' education quality as a function of endogenous school funding and an exogenous component that captures all other determinants of local education quality. To mimic the US school funding system, we include federal and state income taxes and local taxes on rent (proxying property taxes). The reliance on local taxes creates a direct link between local wages, rents, and school funding. This interaction can generate inequality of opportunity because richer families live in more expensive areas that have better-funded schools.

We estimate the model with census data using a two-step estimator. The first step uses data on residential choices to estimate the mean utility that each education and family type attributes to each neighborhood. The second step identifies how types' mean utility in a location depends on their preferences for regional characteristics. In the second step, we use instruments to identify workers' valuation of real wages. We then use residential choices of non-parents to identify the general attractiveness (i.e., unobserved amenities) of a location. Last, we exploit differences in residential choices between parents and nonparents to estimate parents' valuation of local child opportunity values.

We then use our estimated model to evaluate an equalization of school funding across students. The reform raises average funding for low-skill families and reduces it for highskill families. We compare the reform's direct effects, where only education choices adjust, 
with its general equilibrium effects. Direct effects of equalizing school funding are large for low-skill families: Their children's probability of attending college increases by 3.15 percentage points (henceforth p.p.). Effects are smaller in general equilibrium (only +0.6 p.p.) because average education returns decline and low-skill families shift toward locations with lower exogenous education quality. For high-skill families, the reform leads to a small reduction in their children's probability of attending college (-0.5 p.p.). The effect is similar in general equilibrium (-0.3 p.p.) because high-skill families shift toward locations with better exogenous education quality which offsets the decline in average education returns. Our findings are similar when allowing for peer effects in education. We find that the reform increases the geographic variation in education outcomes: Locations with lower exogenous education quality initially tend to have higher school funding. Equalizing funding therefore cuts resources in these locations, further deteriorating their education outcomes. Local wage adjustments mitigate the direct effects of the funding cut because lower education outcomes reduce local skill supply, which increases local skill premia and therefore children's incentives to get educated. In the Appendix, we further evaluate the effects of rent subsidies as an alternative policy to increase equality of opportunity. Overall, our findings emphasize that interactions between local markets, local education quality, and households' education and residential choices are important to evaluate the long-run effects of education policies.

\section{Related Literature}

Our paper relates to several strands of the literature. Seminal work that studies the link between inequality, local human capital formation, and local school financing goes back to Benabou (1993, 1996), Durlauf (1996a,b), and Fernandez and Rogerson (1996, 1997). Most of the work is theoretical with the exception of Fernandez and Rogerson (1998), who develop and calibrate a stylized dynamic general equilibrium model with two locations to study the effects of school finance reforms on income inequality and intergenerational mobility. Other quantitative work on the topics includes contemporaneous work by Durlauf and Seshadri (2017), Fogli and Guerrieri (2019), and Zheng and Graham (2020). Fogli and Guerrieri (2019) study the effects of a skill premium shock on inequality and segregation in an overlapping generations model with two locations and local education spillovers. Zheng and Graham (2020) develop a dynamic heterogeneous agent model with three neighborhoods in which agents choose their residence location and human capital investment. They use the calibrated model to study the effects of school funding reforms and housing vouchers on intergenerational mobility. Our paper embeds the 
mechanisms highlighted by this literature into a quantitative spatial framework with an arbitrary number of locations that allows us to evaluate policies while accounting for interactions between local labor markets, local education environments, and families' education and residential choices.

A large empirical literature studies the causal effects of neighborhoods and school funding on children's education and economic outcomes. Altonji and Mansfield (2018) find that schools and neighborhoods have large effects on children's education and future earnings. Chetty and Hendren (2018b) use administrative tax record data to estimate the causal effects of US counties on children's education and other adulthood outcomes. Recent studies by Jackson et al. (2016) and Biasi (2019) estimate the causal effects of local school funding on children's education and future earnings. More generally, our paper relates to a large literature that studies skill formation and optimal education policies, including Durlauf (2004), Cunha et al. (2010), Fryer and Katz (2013), Abbott et al. (2019), Daruich (2018), and many others. Our paper uses findings from the empirical literature to quantify a spatial general equilibrium model which can evaluate policies and study the macro implications of existing micro estimates. Our analysis intuitively decomposes the causal neighborhood effects from Chetty and Hendren (2018b) into parts due to local labor market access and local education quality. We use the elasticities estimated by Jackson et al. (2016) to incorporate endogenous local school funding as a determinant of local education quality into our quantitative framework.

Another relevant literature studies how workers sort into locations based on local wages or amenities (e.g., Berry and Glaeser (2005), Diamond (2016), Moretti (2013), and Bilal and Rossi-Hansberg (2018)). Other papers study how parents additionally sort into neighborhoods with good local education environments (e.g., Bayer et al. (2007) and Nechyba (2006)). Parents' residential choices are an important way of investing in their children's human capital. We incorporate both motives for residential choices in our model and study their implications in general equilibrium.

To take our framework to the data, we utilize methods from the Quantitative Spatial Economics literature (reviewed in Redding and Rossi-Hansberg (2017)). The dynamic structure of our model relates in particular to Caliendo et al. (2019). This literature has developed tractable frameworks that account for heterogeneity in locations' exogenous characteristics and endogenous interactions between agents' choices and local markets. A central contribution of this literature is to formalize the notion of labor market access (e.g., Redding and Venables (2004), Redding and Sturm (2008), Tsivanidis (2018), and Bryan and Morten (2019)). Loosely speaking, the local market access of an origin location is the wage in all possible destinations weighted by the respective moving costs to 
reach these destinations. Our paper highlights that local labor market access affects not only the static sorting of workers, but also children's returns to education and therefore their educational and economic outcomes. We add to the quantitative spatial literature by incorporating this channel into a dynastic model where local educational and residential choices jointly determine workers' skill distribution across locations. Our framework opens a new avenue to account for changes in both of these decisions when evaluating policy counterfactuals.

\section{Motivating Evidence on local Determinants of EDUCATION OUTCOMES}

This section documents large variation in education outcomes across US commuting zones (henceforth "CZs"), which motivates our analysis. We present differences in skill premia and school funding across CZs, which suggest that CZs differ in returns to education and education quality. Online Appendix B contains a detailed description of data sources and construction.

Geographic Variation in Education Outcomes Conditional on Parental Background. A large literature emphasizes the importance of neighborhoods for children's long-run outcomes (see Durlauf (2004) for a review and Chetty et al. (2014), Chetty et al. (2016), Altonji and Mansfield (2018), and Chetty and Hendren (2018a,b) for more recent work). In Figure 1, we present data from Chetty and Hendren (2018b) on the share of children who attend college in each CZ, separately for families at the 25th (blue bars) and 75th (red bars) percentile of the US income distribution. We order CZs by education outcomes of children from low-income families. The share of children attending college varies substantially across CZs, ranging from 0.35 to 0.8 for low-income families and from 0.7 to almost 1 for high-income families. Chetty and Hendren (2018b) find that a large part of this variation is causal to children's exposure to their childhood location.

Geographic Variation in Returns to Education. Children's future returns to education differ across childhood locations if skill premia vary across locations and moving across locations is costly. With moving costs, childhood locations matter for future residential choices which determine labor market access and returns to education. We provide evidence for this channel using micro-data from the decennial census and the 2006-10 American Community Survey (ACS). We estimate college wage premia for each CZ by regressing individuals' log wages on $\mathrm{CZ}$ and education fixed effects, controlling for a range of 


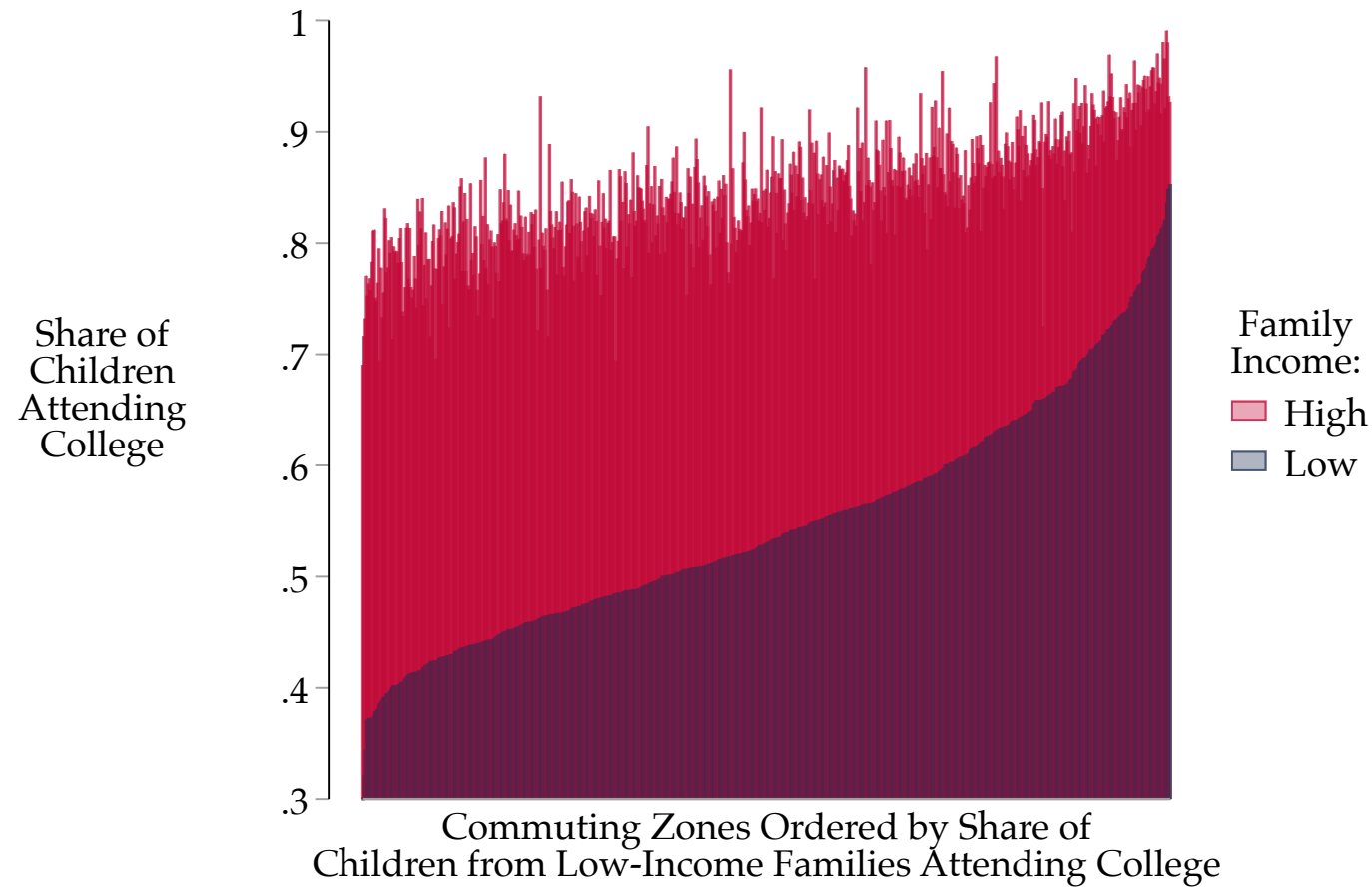

Notes: This figure shows the geographic variation in the share of children attending college across US commuting zones. Blue (red) bars show the share of children attending college whose families are at the 25th (75th) percentile of the US income distribution. We order commuting zones by the college attendance share of children from low-income families. The source of the data is "Online Data Table 4: Complete County-Level Dataset: Causal Effects and Covariates" from Chetty and Hendren (2018b).

demographic characteristics. The estimated college wage premia average 57 percent and vary substantially across $\mathrm{CZs}$ with a standard deviation of 8 percent. Census data show that childhood location matters for future moving choices. In particular, 50 percent of workers between ages 35 and 50 years still live in their state of birth. Even conditional on moving, workers are much more likely to move to locations that are close to their childhood location.

Geographic Variation in Education Quality. Local education quality (i.e., the ease of getting educated) can depend on different local factors, such as school funding, teacher quality, infrastructure, role models, information, culture, peers or others. Local school funding has received particular interest in the public and academic debate because of its policy relevance. Figure 2 shows per student school funding in the ten best and worst funded CZs using data from the National Center for Education Statistics (NCES). Variation is substantial with per student funding ranging from $\$ 7,000$ to more than $\$ 25,000$ across CZs. The composition of funding also differs across CZs, as seen in the color shad- 


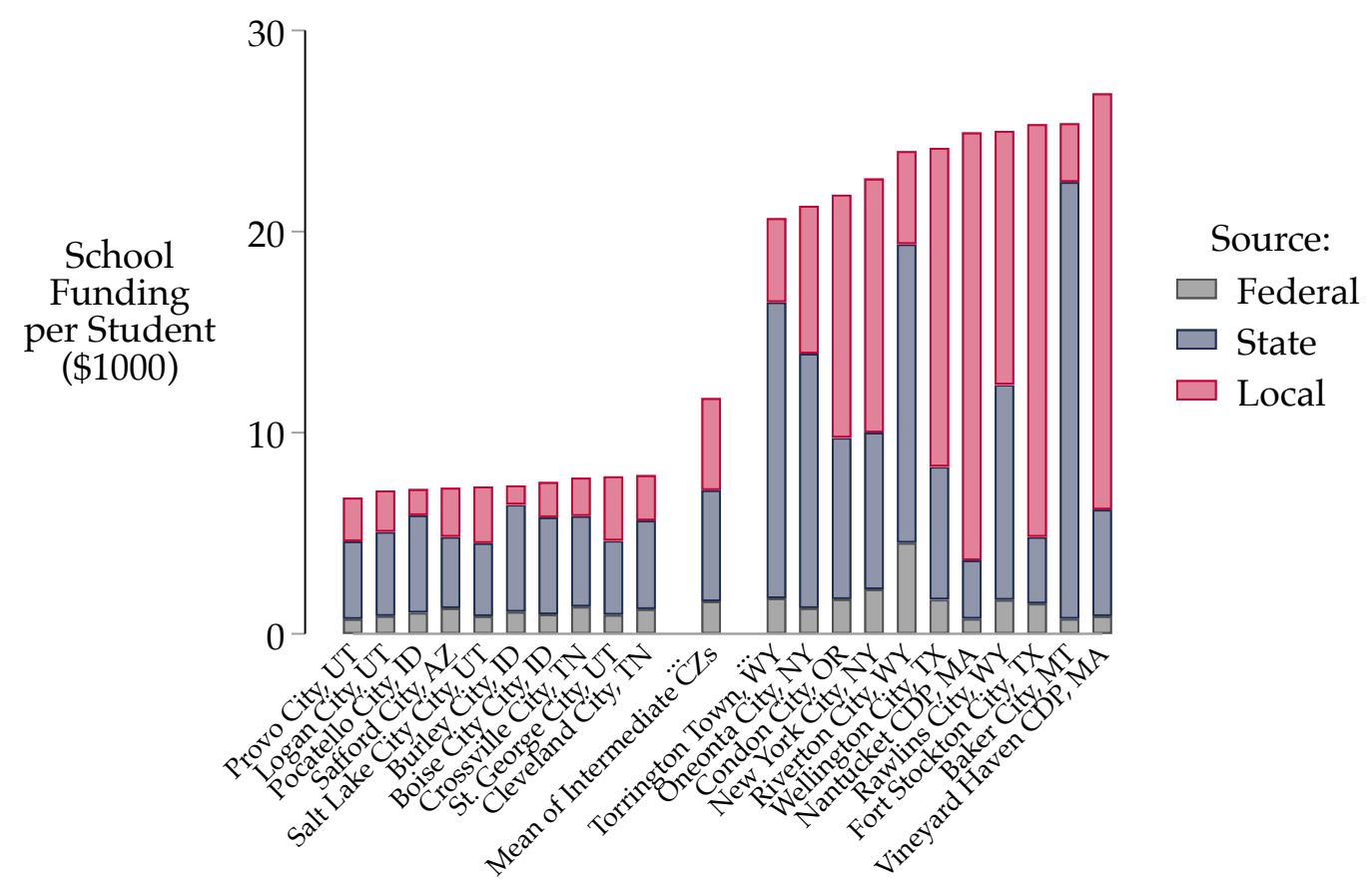

Notes: This figure presents per student school funding in the ten best- and worst-funded commuting zones using 2010 data from the National Center for Education Statistics (NCES). The color shading of the bar graphs indicates the share of funding that is received from federal, state, and local sources. The figure shows large geographic variation in per student school funding and substantial differences in the composition of the funding sources.

ing of Figure 2. On average, better-funded CZs raise more of their resources locally. Recent studies such as Jackson et al. (2016) show that local school funding has large causal effects on children's education outcomes.

\section{A Model of local Human Capital Production AND LOCAL LABOR MARKETS}

Guided by these motivating facts, we now present a spatial equilibrium model that links educational and residential choices to local labor markets and local education quality. In this section, we introduce the core framework that highlights the model's key mechanisms. In the remainder of the paper, we extend and estimate the framework to evaluate the effects of school funding reforms in spatial general equilibrium. 


\subsection{Environment}

Geography. Locations $n$ are separated by bilateral moving costs $\mathcal{C}_{n n^{\prime}}$ which we measure in utils. These moving costs can reflect pecuniary or non-pecuniary costs, such as the time of moving, information frictions, or the psychological cost of being away from one's family or childhood friends. ${ }^{1}$

Worker Characteristics and Preferences. Workers $i$ are characterized by their education $e$ (skill level), which is either low or high, $e=\{l, h\}$, and their location of work $n$. Each worker has one child and receives taste shocks over education levels and locations, which we respectively denote by $\epsilon_{e}^{i}$ and $\epsilon_{n}^{i}$. We use the terms worker, parents, or families interchangeably. Workers value the consumption good on which they spend their entire wage income. We denote the indirect flow utility of workers with education $e$ in location $n$ by $U_{n}^{e}$. Parents are altruistic and discount their children's utility by a factor $\beta$.

Local Labor Markets. Perfectly competitive firms produce a homogeneous, freely traded consumption good with location-specific production technology $Y_{n}=G_{n}\left(L_{n}^{l}, L_{n}^{h}\right)$. Lowand high-skill labor, denoted $L_{n}^{e}$, are inputs into production and can be imperfect substitutes. Local labor market clearing endogenously determines local wages for each skill type, which we denote by $w_{n}^{e}$.

Local Human Capital Production. Education quality $\mathcal{Q}_{n}^{e}$ represents the utility costs of becoming high-skill relative to remaining low-skill. The cost depends on childhood location $n$ and parental education $e$. Education is a binary choice, so we can normalize the cost of remaining low-skill to zero without loss of generality. Education quality can depend on a variety of local factors. Some of the most important ones are likely endogenous as they relate to a location's skill composition (e.g., peer effects or role models) or to local factor prices (e.g., local resources or tax revenues). We therefore define local education quality as a general function of the endogenous wage and worker distribution across locations and skill levels: $\mathcal{Q}_{n}^{e} \equiv \mathcal{Q}_{n}^{e}\left(\left\{L_{n}^{e}\right\},\left\{w_{n}^{e}\right\}\right)$. An exogenous local component can capture additional local factors that matter for education quality.

\subsection{Location and Education Choice Problem}

Timeline and Decisions. Individuals live for two periods: childhood and adulthood. Children are born to parents with education $e$ and are raised in childhood location $n$

\footnotetext{
${ }^{1}$ Information frictions can be important because uncertainty about the economic conditions in other locations can affect moving choices. See Porcher (2019) for a study of information frictions in a spatial framework.
} 
(which was chosen by their parents). They receive idiosyncratic education taste shocks, $\epsilon_{e^{\prime}}^{i}$ and then choose their education $e^{\prime}$. Education choices additionally depend on local returns to education and local education quality. After finishing their education, children become young adults and have their own children. The previous adult generation dies. Young adults then learn their idiosyncratic location taste shocks, $\epsilon_{n^{\prime}}^{i}$, and choose their adulthood location in which they work and raise their children. Parents are altruistic, so their residential choices consider the utility that destinations offer to their children. Residential and educational choices are forward-looking, so our model is dynastic and each time period represents one generation.

Dynamic Decision Problem. Young adults with education level $e$ and childhood location $n$ choose their adulthood location $n^{\prime}$ by solving the following maximization problem:

$$
V(n, e)=E_{\epsilon_{n^{\prime}}} \max _{n^{\prime}}\left\{U_{n^{\prime}}^{e}-\mathcal{C}_{n n^{\prime}}+\epsilon_{n^{\prime}}+\beta O\left(n^{\prime}, e\right)\right\},
$$

where $U_{n^{\prime}}^{e}$ is the flow utility in each destination, $\mathcal{C}_{n n^{\prime}}$ is the bilateral moving cost, and $\epsilon_{n^{\prime}}$ is the idiosyncratic location taste shock. $V(n, e)$ is the expected utility value of young adults before moving, where the expectation is taken over their idiosyncratic location taste shocks. $O\left(n^{\prime}, e\right)$ is the expected utility of children who are born to parents of education $e$ and are raised in childhood location $n^{\prime}$. We call this utility local "child opportunity value" and it is given by:

$$
O\left(n^{\prime}, e\right)=E_{\epsilon_{e^{\prime}}} \max _{e^{\prime}}\left\{1_{e^{\prime}=h} \mathcal{Q}_{n^{\prime}}^{e}+\epsilon_{e^{\prime}}+V\left(n^{\prime}, e^{\prime}\right)\right\} .
$$

The expectation is taken over children's idiosyncratic education taste shocks $\epsilon_{e^{\prime}} . V\left(n^{\prime}, e^{\prime}\right)$ is the expected continuation value that location $n^{\prime}$ offers to young adults of the next generation who obtain education level $e^{\prime}$.

Solving Education and Location Choices. To solve education and location choices, we make the following assumption, which is standard in the discrete choice literature:

Assumption 1. Idiosyncratic taste shocks over locations $\epsilon_{n}$ and education levels $\epsilon_{e}$ are drawn i.i.d. from a Gumbel distribution with mean zero and dispersion parameters $\sigma_{N}$ and $\sigma_{E}$.

Under this assumption, we can aggregate individuals' choices into the shares of each type that makes a given decision. We can also express expected value functions in closed form. We solve families' problem backwards, starting with children's education choice. The share of children in location $n$ with parents of education $e$ who choose education $e^{\prime}$ 
is:

$$
\operatorname{Pr}\left(e^{\prime} \mid n, e\right)=\frac{\exp \left(\frac{1}{\sigma_{E}} 1_{e^{\prime}=h} \mathcal{Q}_{n}^{e}+\frac{1}{\sigma_{E}} V\left(n, e^{\prime}\right)\right)}{\sum_{e^{\prime}} \exp \left(\frac{1}{\sigma_{E}} 1_{e^{\prime}=h} \mathcal{Q}_{n}^{e}+\frac{1}{\sigma_{E}} V\left(n, e^{\prime}\right)\right)} .
$$

Child opportunity values for these children (before knowing education taste shocks) are:

$$
O(n, e)=\sigma_{E} \log \left[\sum_{e^{\prime}} \exp \left(\frac{1}{\sigma_{E}} 1_{e^{\prime}=h} \mathcal{Q}_{n}^{e}+\frac{1}{\sigma_{E}} V\left(n, e^{\prime}\right)\right)\right] .
$$

Similarly, the share of young parents with education $e$ who move from their childhood location $n$ to adulthood location $n^{\prime}$ is:

$$
\operatorname{Pr}\left(n^{\prime} \mid n, e\right)=\frac{\exp \left(\frac{1}{\sigma_{N}} U_{n^{\prime}}^{e}-\frac{1}{\sigma_{N}} \mathcal{C}_{n n^{\prime}}+\frac{\beta}{\sigma_{N}} O\left(n^{\prime}, e\right)\right)}{\sum_{n^{\prime}} \exp \left(\frac{1}{\sigma_{N}} U_{n^{\prime}}^{e}-\frac{1}{\sigma_{N}} \mathcal{C}_{n n^{\prime}}+\frac{\beta}{\sigma_{N}} O\left(n^{\prime}, e\right)\right)} .
$$

The expected utility of these young adults (before knowing location taste shocks) is:

$$
V(n, e)=\sigma_{N} \log \sum_{n^{\prime}} \exp \left[\frac{1}{\sigma_{N}} U_{n^{\prime}}^{e}-\frac{1}{\sigma_{N}} \mathcal{C}_{n n^{\prime}}+\frac{\beta}{\sigma_{N}} O\left(n^{\prime}, e\right)\right] .
$$

\subsection{Aggregation and Equilibrium}

Aggregate Law of Motion. Individuals' educational and residential choices determine how the distribution of workers across education levels and locations evolves dynamically over generations. The law of motion (with time subscripts) is given by:

$$
L_{n^{\prime}, t}^{e^{\prime}}=\sum_{n} \operatorname{Pr}_{t}\left(n^{\prime} \mid n, e^{\prime}\right) \sum_{e} \operatorname{Pr}_{t-1}\left(e^{\prime} \mid n, e\right) L_{n, t-1}^{e}
$$

On the right, we start with workers $L_{n, t-1}^{e}$ from generation $t-1$ who have education $e$ and who work and raise their children in location $n$. A fraction $\operatorname{Pr}\left(e^{\prime} \mid n, e\right)$ of these children obtains education $e^{\prime}$. Summing across parental education $e$ yields the mass of young adults from generation $t$ who have education $e^{\prime}$ and grew up in location $n$. A fraction $\operatorname{Pr}\left(n^{\prime} \mid n, e^{\prime}\right)$ of these young adults then moves to adulthood location $n^{\prime}$. Summing across childhood locations $n$ yields generation $t^{\prime} s$ distribution of adults across education levels $e^{\prime}$ and adulthood locations $n^{\prime}$. In the steady state, this distribution is constant across generations, so that $L_{n^{\prime}, t}^{e^{\prime}}=L_{n, t-1}^{e}$ holds for all $t .^{2}$

Market Clearing. Profit-maximizing firms in each location $n$ determine local labor demand by skill type. Workers' educational and residential choices determine local labor

\footnotetext{
${ }^{2}$ In the steady state, young adults can still move across locations. Education levels can also change across generations within a given dynasty. In the stationary equilibrium, these changes balance so that the aggregate adult population of each skill type remains constant in each location.
} 
supply. Wages for each skill type $w_{n}^{e}$ adjust in each location to clear local labor markets.

Equilibrium. The exogenous parameters of our model consist of structural parameters and time-varying "regional characteristics." Given a path of these exogenous parameters $\left\{\Omega_{t}\right\}_{t=0}^{\infty}$ and an initial distribution of workers $L_{n, 0}^{e}$, the recursive competitive equilibrium is defined by the paths of:

(i) families' residential and education choices for each education type and location $\left\{\operatorname{Pr}_{t}\left(n^{\prime} \mid\right.\right.$ $\left.n, e), \operatorname{Pr}_{t}\left(e^{\prime} \mid n, e\right)\right\}_{t=0}^{\infty}$, (ii) value functions for each education type and location $\left\{V_{t}(n, e)\right\}_{t}^{\infty}$, (iii) the distribution of workers across education types and locations $\left\{L_{n, t}^{e}\right\}_{t=0^{\prime}}^{\infty}$ and (iv) local factor prices $\left\{w_{n, t}^{e}\right\}_{t=0^{\prime}}^{\infty}$ such that:

1. Residential and education choices maximize families' utility as derived in Equations (2) and (4);

2. Value functions are consistent with Equations (3) and (5);

3. The distribution of workers across education levels and locations is consistent with the law of motion in Equation (6);

4. Wages for each education level clear labor markets in each location and period.

\subsection{Model Implications}

The central equation of our model links children's education outcomes to local education quality and local returns to education (conditional on parental education $e$ ). We can express the odds of becoming high-skill relative to remaining low-skill as (cf. Equation 2):

$$
\underbrace{\log \left(\frac{\operatorname{Pr}(h \mid n, e)}{\operatorname{Pr}(l \mid n, e)}\right)}_{\text {High-Skill Odds }}=\underbrace{\frac{1}{\sigma_{E}}(V(n, h)-V(n, l))}_{\text {Return to Education }}+\underbrace{\frac{1}{\sigma_{E}} \mathcal{Q}_{n}^{e}\left(\left\{L_{n}^{e}\right\},\left\{w_{n}^{e}\right\}\right)}_{\text {Education Quality }} .
$$

The first determinant of local education choices is children's future return to education. In each childhood location, local education returns are equal to the difference in continuation values for high- versus low-skill young adults. Continuation values depend on education level and childhood location because it is costly to move and locations differ in wages and skill premia. Continuation values in each childhood location therefore capture the ability of young local workers to access labor markets where wages for their education level are high. We refer to this determinant interchangeably as "local labor market access" or "local returns to education". 
Local education quality is the second determinant of education choices. It captures children's utility cost of becoming high-skill relative to remaining low-skill in each location. To study specific policy questions, local education quality can be parameterized as a function of different exogenous or endogenous model moments, such as local factor prices or local skill composition.

An important feature of our model is that locations' education returns, education quality, prices, and the distribution of workers across locations and education levels are all endogenous and interact with each other through families' residential and educational choices. To evaluate policies, our framework therefore accounts for the direct effects of policies and the indirect ones that operate through the feedback effects in spatial general equilibrium.

\section{REFORMing THE US EdUCATION SYSTEM IN SPATIAL GENERAL EQUILIBRIUM}

We now extend and estimate our core framework to study the effects of school funding reforms on local education outcomes and social mobility in the aggregate and across locations. Schools in the US are funded from federal, state, and local taxes. Differences in local school funding are large (cf. Figure 2), and they have been the subject of a long and fierce political debate. The reliance on local tax revenues creates a feedback between local prices and local school resources. Locations with higher rents have higher tax revenues and therefore better-funded schools. Better schools can attract more high-income families, which further increases rents, tax revenues, and school funding. Poor families cannot afford the rent in these locations, depriving their children of access to high-quality schools. We formalize this relationship between local prices and local school quality in our model and study its implications in our counterfactual analysis.

\subsection{Quantitative Model: Additional Ingredients and Assumptions}

We enrich our core framework to incorporate local school funding, taxes, and other elements that allow us to take the model to the data.

Family Types. We now allow workers to differ not only by education $e$ but also by parent status $k$. We indicate workers who have children by $k=1$ and those who do not by $k=0$. Fertility is exogenously determined by probabilities $\operatorname{Pr}(k \mid e)$, which can differ across 
education types. Parents of education $e$ have $1 / \operatorname{Pr}(k=1 \mid e)$ children to keep population constant.

Nested Geography. We consider a nested geography with multiple local labor markets, indexed by $m \in \mathbb{M}$. Each labor market consists of several neighborhoods, indexed by $n \in$ $\mathbb{N}_{m}$. Moving across labor markets incurs a $\operatorname{cost} \mathcal{C}_{m m^{\prime}}^{e k}$, which can differ across education and family types $e k$.

Neighborhood Housing Markets and Amenities. Neighborhoods have a fixed housing supply $\mathcal{H}_{n}$. Rental markets clear in each neighborhood, which determines local rents $r_{n}$. We reimburse aggregate rent payments to workers in proportion to their wage income. ${ }^{3}$ Neighborhoods differ in amenities $\mathcal{A}_{n}^{e k}$, which capture regional characteristics that make a neighborhood more or less desirable for each education and family type $e k$.

Neighborhood Education Quality. We specify local education quality $\mathcal{Q}_{n}^{e}$ as a function of endogenous per student school funding $f_{n}$ and an exogenous local component $\mathcal{K}_{n}^{e}$ as:

$$
\mathcal{Q}_{n}^{e}=\gamma^{e} \log \left(f_{n}\right)+\mathcal{K}_{n}^{e},
$$

where $\gamma^{e}$ is the causal effect of school funding on education quality. The exogenous component captures all remaining factors that are important for local education environments.

School Funding and Taxation. School funding is raised through federal and state income taxes and local rent taxes, which we denote by $\tau_{g}^{w}, \tau_{s}^{w}$, and $\tau_{n}^{r}$. School funding therefore depends on local prices and the distribution of workers across skills, family types, and locations. Federal and state governments distribute their tax revenues to neighborhoods $n$ according to school funding allocation rules, which we denote by $\delta_{n}^{g}$ and $\delta_{n}^{s}$. Each neighborhood allocates its entire tax revenue to local schools.

Functional Forms for Production Technology and Preferences. Production technologies differ across labor markets and have a constant elasticity of substitution over low- and high-skill labor, so that:

$$
G_{m}\left(L_{m}^{l}, L_{m}^{h}\right)=\mathcal{Z}_{m}\left[\mathcal{S}_{m}^{l}\left(L_{m}^{l}\right)^{\rho}+\mathcal{S}_{m}^{h}\left(L_{m}^{h}\right)^{\rho}\right]^{\frac{1}{\rho}},
$$

where $\rho$ determines the elasticity of substitution, $\mathcal{Z}_{m}$ is total factor productivity, and $\mathcal{S}_{m}^{e}$ are factor shares that add to one across skill types: $\mathcal{S}_{m}^{h}+\mathcal{S}_{m}^{l}=1$.

\footnotetext{
${ }^{3}$ Each worker receives a payment of $D w$, where the dividend $D$ equals the ratio between the economy's total rent payment and total wage income. This reimbursement can mimic dividends that households would receive from investing an amount proportional to their wage income in a national real estate portfolio.
} 
Families have Cobb-Douglas preferences over the consumption good $C$ and housing $H$. Amenities $\mathcal{A}_{n}^{e k}$ enter the utility function additively, so families' utility is given by:

$$
U=\mathcal{A}_{n}^{e k}+\log \left[\left(\frac{H}{\alpha^{e k}}\right)^{\alpha^{e k}}\left(\frac{C}{1-\alpha^{e k}}\right)^{1-\alpha^{e k}}\right],
$$

where $\alpha^{e k}$ is the housing expenditure share.

\subsection{Solving the Quantitative Model}

The model solution is similar to the core model that we presented in Section 3. We summarize the most important solution steps here and provide the full set of equations in Online Appendix A.

Static Choice between Housing and Consumption Goods. In each period, families of type $e k$ in location $n$ choose housing units $H$ and consumption good $C$ to maximize their utility (Equation (10)) subject to a budget constraint. This derives the following indirect utility where $Y_{n}^{e}$ is disposable income:

$$
U_{n}^{e k}=\mathcal{A}_{n}^{e k}+\log \left(Y_{n}^{e}\right)-\alpha^{e k} \log \left(r_{n}\right) .
$$

Dynamic Decision Problem. To express families' education and residential choice problem, we must now adjust indices to the nested geography and family types $k$. Families learn whether or not they have children after finishing their education and before moving to their adulthood location. Value functions of young adults with education $e$, family type $k$, and childhood labor market $m$ before moving are given by:

$$
V(m, e, k)=\mathbb{E}_{\epsilon_{n^{\prime}}} \max _{n^{\prime} \in \mathbb{N}}\left\{U_{n^{\prime}}^{e k}-\mathcal{C}_{m m^{\prime}}^{e k}+\sigma_{N} \epsilon_{n^{\prime}}+1_{k=1} \beta O\left(n^{\prime}, e\right)\right\},
$$

where we now multiply the continuation value with an indicator that is equal to one if the family has children and zero otherwise. Parents' residential choices are dynamic because they value destinations' child opportunity values. Non-parents do not value child opportunity values so their residential choices are static. Wages $w_{m}^{e}$, moving costs $\mathcal{C}_{m m^{\prime}}^{e k}$ and value functions $V(m, e, k)$ vary across labor markets, while rent $r_{n}$, education quality $Q_{n}^{e}$ and child opportunity values $O(n, e)$ vary across neighborhoods. ${ }^{4}$

\footnotetext{
${ }^{4}$ Value functions vary across childhood locations due to bilateral moving costs. It follows that value functions only depend on labor markets (and not neighborhoods) because we assume that moving is costly across labor markets but not within.
} 
Children's likelihood of becoming high-skill relative to remaining low-skill is given by:

$$
\underbrace{\log \left(\frac{\operatorname{Pr}(h \mid n, e)}{\operatorname{Pr}(l \mid n, e)}\right)}_{\text {High-Skill Odds }}=\underbrace{\frac{1}{\sigma_{E}}(R(m, h)-R(m, l))}_{\text {Return to Education }}+\underbrace{\frac{1}{\sigma_{E}} \mathcal{K}_{n}^{e}}_{\text {Exog. Educ. Quality }}+\underbrace{\frac{\gamma^{e}}{\sigma_{E}} \log \left(f_{n}\right)}_{\text {Funding }},
$$

As before, education returns in each childhood location are given by the difference in expected continuation values for high-skill versus low-skill young adults. We define young adults' expected continuation values before knowing their fertility shocks as: $R(m, e) \equiv$ $\sum_{k} \operatorname{Pr}(k \mid e) V(m, e, k)$. Local education quality $\mathcal{Q}_{n}^{e}$ consists of endogenous local school funding $f_{n}$ and the local exogenous component $\mathcal{K}_{n}^{e}$.

\subsection{Market Clearing and Recursive Equilibrium}

Law of Motion. Individuals' education and residential choices and their exogenous fertility shocks determine how the distribution of workers evolves dynamically across neighborhoods, education levels, and family types.

Market Clearing. Labor market clearing determines local wages for each skill type $w_{m}^{e}$. Rental market clearing in each neighborhood determines local rents $r_{n}$.

Equilibrium. Exogenous parameters include structural parameters, tax rates, school funding allocation rules from federal, state, and local governments, and time-varying regional characteristics. Conditional on these exogenous parameters, the definition of equilibrium is similar to that of our core framework presented in Section 3. Endogenous factor prices are now local wages and rents $\left\{w_{m t}^{e}, r_{n t}\right\}$.

\section{CAlibRATION AND ESTIMATION}

When taking our model to the data, we interpret labor markets $m$ as commuting zones (following Tolbert and Sizer (1996)) and neighborhoods $n$ as counties. ${ }^{5}$ There are 741 commuting zones (CZs) and 3,100 counties in the United States. CZs are constructed to have strong commuting ties within and weak commuting ties across their boundaries. This definition is in line with our model in which labor markets are separated by moving costs. Individuals whose highest education level is high school are considered low-skill. All others are considered high-skill. Households in which a child under 18 is currently

\footnotetext{
${ }^{5}$ Our analysis focuses on counties, instead of smaller units such as school districts, because causal effect estimates from Chetty and Hendren (2018b) are only available at the county level.
} 
present are considered parents. ${ }^{6}$

The estimation of our model relies on six key data moments: moving flows across CZs, residential choices within CZs, CZ-level wages, and at the county level rents, education choices for children from high- and low-skill families, and per student school funding by funding source (federal, state, local). We provide more information about the data construction and summary statistics in the Online Appendix B.

We identify the model's structural parameters with a mix of calibration and estimation strategies. As a last step, we follow the Quantitative Spatial Economics (QSE) literature and infer regional characteristics as structural residuals by fitting our model predictions to regional data moments. In this section, we describe the calibration, estimation, and inference of regional characteristics. Online Appendix $C$ provides additional information and derivations.

\subsection{Calibrated Parameters}

We now discuss the calibration of the parameters that relate to local school funding. Table 1 describes our calibration strategy and presents results for additional calibrated parameters.

Effects of School Funding on Education Outcomes. We use estimates from the literature to identify the causal effect of per student school funding on the probability of attending college. In particular, we rely on Jackson et al. (2016), who use exogenous variation in school funding from court-mandated reforms to estimate the effects of school funding on children's probability of attending (and graduating from) college. Effects are separately estimated for children from low- and high-skill families. ${ }^{7}$ We map the authors' linear 2SLS estimates to our model by taking the derivate of Equation 12 with respect to school funding so that:

$$
\gamma^{e, 2 S L S}= \begin{cases}\left.\frac{\Delta \operatorname{Pr}(h \mid n, e)}{\Delta \log \left(f_{n}\right)}\right|_{m} & \text { in Jackson et al. (2016) and } \\ \left.\frac{\partial \operatorname{Pr}(h \mid n, e)}{\partial \log \left(f_{n}\right)}\right|_{m}=\frac{\gamma^{e}}{\sigma_{E}} \operatorname{Pr}(h \mid n, e)(1-\operatorname{Pr}(h \mid n, e)) & \text { in our model. }\end{cases}
$$

${ }^{6}$ If families had a child in the past, we consider them to be "non-parents" if the child no longer lives in the household. This classification is reasonable because only households where a child is currently present value local education environments at that moment of time.

${ }^{7}$ The authors kindly provided us with these estimates, since their published paper does not include this exact model specification that best maps to the structural parameters of our model. We are very grateful to the authors and in particular Rucker Johnson for their time and effort in providing these results. 
TABle 1: OVERVIEW OF CAlibrated PARAMETERS

\begin{tabular}{|c|c|c|}
\hline Parameter & Calibration Data or Source & Results \\
\hline Wage and Rent Tax & $\begin{array}{l}\text { Wages, rents, and school fund- } \\
\text { ing (Decennial Census, ACS, } \\
\text { and NCES). }\end{array}$ & $\begin{array}{l}\tau_{g}^{w}=1.6 \% \\
\tau_{s}^{w}=\{6.1 \%, 1.7 \%\} \\
\tau_{n}^{r}=\{14.9 \%, 9.8 \%\} \\
\text { (mean, std) }\end{array}$ \\
\hline Effect of School Funding & $\begin{array}{l}\text { Causal 2SLS estimates from } \\
\text { Jackson et al. (2016). }\end{array}$ & $\begin{array}{l}\gamma^{l} / \sigma_{E}=2.43 \\
\gamma^{h} / \sigma_{E}=2.25\end{array}$ \\
\hline Housing Expenditure Share & $\begin{array}{l}\text { Microdata on expenditure } \\
\text { (CEX 2011). }\end{array}$ & $\begin{array}{l}\alpha^{l 0}=0.34, \alpha^{h 0}=0.33 \\
\alpha^{l 1}=0.38, \alpha^{h 1}=0.36\end{array}$ \\
\hline Probability of Having a Child & $\begin{array}{l}\text { Share of individuals with chil- } \\
\text { dren by skill (Decennial Cen- } \\
\text { sus, ACS). }\end{array}$ & $\begin{array}{l}\operatorname{Pr}(\mathrm{k}=1 \mid \mathrm{l})=0.56 \\
\operatorname{Pr}(\mathrm{k}=1 \mid \mathrm{h})=0.63\end{array}$ \\
\hline Skill Substitutability & $\begin{array}{l}\text { Estimates from Ciccone and } \\
\text { Peri (2005). }\end{array}$ & $\rho=1 / 3$ \\
\hline
\end{tabular}

Notes: This table documents calibrated parameters using our baseline sample from 2010, which restricts population to ages 35 to 44 years. The final sample consists of 2,840 counties. We trim local tax rates on rent at the 1st and 99th percentile. NCES denotes the "National Center for Education Statistics," CEX is the "Consumer Expenditure Survey," and ACS the "American Community Survey."

The 2SLS estimation controls for location fixed effects, so that we hold regional characteristics constant and assume $\partial R(m, e) / \partial f_{n}=0$ when taking the derivative.

Jackson et al. (2016) find that a 10 percent increase in school funding increases children's probability of attending (and graduating from) college by 7 (4.6) percentage points for low-skill parents. For high-skill parents, children's probability of graduating from college increases by 3.2 percentage points and effects on the probability of attending college are not significant. Averaging these values, we set $\gamma^{l, 2 S L S}=0.58$ and $\gamma^{h, 2 S L S}=0.29$. Using the relationship in Equation 13 and data on the national average of college-attendance probabilities from Chetty and Hendren (2018b), we find that $\gamma^{e} / \sigma_{E}=\{2.43,2.25\}$ for children from low- and high-skill families.

Tax Rates. We calibrate tax rates to county-level data on school funding from federal, state, or local governments. All tax revenue in our model is used for school funding and each level of government balances its budget. Governments' budget constraints therefore directly link school funding to tax rates and local wages or rents. We use this mapping to calibrate federal and state income taxes and local rent taxes. Table 1 shows the results. The federal income tax rate is 1.6 percent. State income taxes average 6.1 percent with 
a standard deviation of 1.7 percent. Local tax rates on rent average 14.9 percent with a standard deviation of 9.8 percent. Local tax rates have a large variation because counties differ in school funding and in the extent to which their schools are funded from the federal, state, or local government (cf. Figure 2).

TABle 2: OVERVIEW OF Estimation STRATEGY

\begin{tabular}{|c|c|c|}
\hline Description & Symbol & Estimation Strategy \\
\hline \multicolumn{3}{|c|}{$\begin{array}{l}\text { Panel A: Auxiliary Terms and Model Objects } \\
\text { (Step } 1 \text { of Estimation, Used in Step 2) }\end{array}$} \\
\hline Moving Cost & $c_{m m^{\prime}}^{e k} \equiv \mathcal{C}_{m m^{\prime}}^{e k} / \sigma_{N}$ & $\begin{array}{l}\text { Parameterized and estimated from moving } \\
\text { flows across CZs. }\end{array}$ \\
\hline CZ-Utility & $u_{m}^{e k} \equiv \mathcal{U}_{m}^{e k} / \sigma_{N}$ & Estimated from moving flows across CZs. \\
\hline County-Utility & $x_{n}^{e k} \equiv \mathcal{X}_{n}^{e k} / \sigma_{N}$ & $\begin{array}{l}\text { Estimated from CZ-utility and county popula- } \\
\text { tion stocks. }\end{array}$ \\
\hline Value Function & $\begin{array}{c}v(e, k, m) \equiv \\
V(e, k, m) / \sigma_{N}\end{array}$ & Estimated from CZ-utility and moving costs. \\
\hline
\end{tabular}

Panel B: Model Parameters

(Step 2 of Estimation)

\begin{tabular}{lll}
$\begin{array}{l}\text { Dispersion of } \\
\text { County Taste } \\
\text { Shock }\end{array}$ & $\sigma_{N}$ & $\begin{array}{l}\text { Identified from relationship between changes } \\
\text { in county-utility and exogenous variation in } \\
\text { changes of real income. }\end{array}$ \\
$\begin{array}{ll}\text { Altruism } \\
\text { chentents }\end{array}$ & $\begin{array}{l}\text { Identified from the extent to which parents sort } \\
\text { more into neighborhoods with higher child op- } \\
\text { portunity values than non-parents. }\end{array}$ \\
$\begin{array}{l}\text { Dispersion of } \\
\text { Education Taste }\end{array}$ & $\sigma_{E}$ & $\begin{array}{l}\text { Identified from relative weight that parents } \\
\text { place on local education probabilities compared } \\
\text { to local continuation values. }\end{array}$ \\
\hline
\end{tabular}

Notes: Panel A of this table describes the first step of our estimation, which estimates model objects and auxiliary terms. Panel B describes the second step, in which we decompose types' county-utilities into the preference weights that each type places on different regional characteristics.

School Funding Allocation Rules. We set funding allocation rules to approximate the current distribution of per student school funding across counties. For the federal (and each state) government, we define the allocation rule to each county $n$ as the relative amount of funding that a student in county $n$ receives compared to the average student in the nation (state). Conditional on tax rates and school funding allocation rules, each 
county's per student funding is endogenously determined by wages and rents.

\subsection{Estimated Parameters}

To estimate the remaining model parameters, we use a two-step estimator that was developed in the empirical industrial organization literature (cf. Berry et al. (2004)) and used in many relevant applications (e.g., Artuç and McLaren (2015) and Diamond (2016)). We interpret the data to reflect a transitional period in our model instead of its steady state. ${ }^{8}$ The first step of the estimator uses individuals' residential choices to estimate the average utility that each type attributes to each county. We denote this utility by $x_{n}^{e k}$. In this step, we additionally estimate value functions and moving costs (i.e., all objects listed in Table 2, Panel A). The second step decomposes mean county utilities into the weights that each education-family-type places on local rents, wages, and child opportunity values. These weights correspond to the dispersion of location and education taste shocks $\left(\sigma_{N}, \sigma_{E}\right)$ and parental altruism $\beta$. In this estimation, we normalize utility by the dispersion of neighborhood taste shocks $\sigma_{N}$ and we denote normalized terms in small caps (cf. definitions in Table 2). Online Appendix $C$ contains the derivations of all expressions used in the estimation.

\section{Step 1: Estimation of Mean County-Utility}

We define average county-utility $x_{n}^{e k}$ for each family-education type as:

$$
x_{n}^{e k} \equiv a_{n}^{e k}+\frac{1}{\sigma_{N}} I_{n}^{e k}+1_{k=1} \beta o(n, e),
$$

where $a_{n}^{e k}$ are local amenities, $I_{n}^{e k}$ is real income, and $o(n, e)$ are child opportunity values. Individuals of a given education-family type value these regional characteristics equally. Model objects and regional characteristics that are measured in utils (such as amenities and child opportunity values) are now re-normalized. The first step estimates average county-utilities from observed residential choices. This approach relies on revealed preferences and requires no assumptions on expectations. In our nested geography, moving is costly across CZs but not within them. We therefore first estimate average CZ-utilities and moving costs from observed moving flows across CZs. We then identify relative countyutilities within each CZ from the population stocks in each county. We now provide more

\footnotetext{
${ }^{8}$ We do so because data from 1990, 2000, and 2010 show that the economy is not in the steady state. In particular, we observe positive net moving flows across CZs and educational deepening, (i.e., more children go to college compared to their parents' generation). In the steady state, population size and skill composition are constant in each CZ.
} 
details on this estimation strategy.

Estimation of CZ-Utilities and Moving Costs. For a given education-family type, our model predicts that moving flows from childhood CZ $m$ to destination $\mathrm{CZ} \mathrm{m}^{\prime}$ are given by:

$$
L_{m m^{\prime}}^{e k}=\frac{\exp \left(u_{m^{\prime}}^{e k}-c_{m m^{\prime}}^{e k}\right)}{\sum_{m^{\prime \prime} \in \mathbb{M}} \exp \left(u_{m^{\prime \prime}}^{e k}-c_{m m^{\prime \prime}}^{e k}\right)} \tilde{L}_{m}^{e k},
$$

where $u_{m}^{e k}$ are average CZ-utilities, $c_{m m^{\prime}}^{e k}$ are bilateral moving costs, and $\tilde{L}_{m}^{e k}$ denotes the number of young adults of type $e k$ in location $m$ before making their moving decision. We parameterize moving costs as a function of type-specific coefficients $\lambda^{\text {ek }}$ and origindestination-specific data moments $X_{m m^{\prime}}: c_{m m^{\prime}}^{c k}=\lambda^{e k} X_{m m^{\prime}}$. For these data moments, we use distance, distance squared, and dummies that indicate whether a move between two CZs changes states, geographic divisions, urban status or coast status. Using this parameterization, we write Equation (15) as:

$$
L_{m m^{\prime}}^{e k}=\exp \left\{\text { dest }_{m^{\prime}}^{e k}-\lambda^{e k} X_{m m^{\prime}}+\text { orig }_{m}^{e k}\right\}+\epsilon_{m m^{\prime}}
$$

where destination fixed effects $d e s t_{m^{\prime}}^{e k}$ correspond to CZ-utilities $u_{m^{\prime}}^{e k}$. CZ-utilities capture the attractiveness or the pull-factor of each destination. Origin fixed effects orig ${ }_{m}^{e k}$ absorb the outside option and origin labor stocks. We use data on moving flows across CZs to estimate Equation (16) separately for each education and family type via Poisson pseudomaximum likelihood (PPML). ${ }^{9}$ The estimation simultaneously identifies each type's CZutilities and moving costs up to a constant of normalization. We normalize the cost of staying to zero without loss of generality.

Construction of County-Utilities. Due to perfect mobility within CZs, we can identify relative county-utilities within each $\mathrm{CZ}$ from data on counties' population stocks as follows:

$$
\exp \left(x_{n}^{e k}\right)=\frac{L_{n}^{e k}}{L_{m}^{e k}} \exp \left(u_{m}^{e k}\right),
$$

where average county-utility $x_{n}^{e k}$ depends on CZ-utility $u_{m}^{e k}$ and the share of that CZ's population that lives in county $n \in m$.

\footnotetext{
${ }^{9}$ PPML estimates the equation in levels and not logs, so the estimator can account for moving flows that are zero. This is important in our context, since we observe only a subset of all movers and observed moving flows are zero between many locations. Other advantages of PPML are discussed in Silva and Tenreyro (2006).
} 
Construction of Value Functions. We further use our estimates of CZ-utility and moving costs to construct value functions for each education-family type, which are given by:

$$
v(m, e, k)=\log \sum_{m^{\prime} \in \mathbb{M}} \exp \left(u_{m^{\prime}}^{e k}-c_{m m^{\prime}}^{e k}\right) .
$$

This equation shows that young families' value functions depend on the utility offered by all possible destinations and the cost that these families have to pay to reach these destinations from their childhood location $m .^{10}$

\section{Step 2: Estimation of Model Parameters}

In the second step of the estimation, we identify the remaining model parameters $\left(\sigma_{N}, \sigma_{E}, \beta\right)$ by decomposing the estimated county-utilities into the weights that each type places on regional characteristics.

To identify the dispersion of location taste shocks, $\sigma_{N}$, we use county-utilities of nonparents, which are given by:

$$
x_{n}^{e 0}=a_{n}^{e 0}+\frac{1}{\sigma_{N}} I_{n}^{e 0}
$$

where $I_{n}^{e k}$ is real disposable income, which is known from the data. It is challenging to identify $\sigma_{N}$ because local amenities $a_{n}^{e k}$ are unobservable and correlate with local real income. To overcome this challenge, we follow Diamond (2016) and use exogenous variation in changes in real income from Bartik-like local labor demand shocks and local housing supply elasticities. The intuition behind the local labor demand shocks is that national changes in industry productivity differentially affect locations based on their initial industrial composition (Bartik (1991)). To construct these labor demand shocks, we compute national changes in industry-level wages and weigh them by locations' industry-level employment in 1980. We do this separately for low- and high-skill workers. We proxy local housing supply elasticities with land-use regulation from Gyourko et al. (2008). Locations' housing supply elasticities provide additional variation because they affect how local wages, rents, and population stocks respond to exogenous labor demand shocks. We use these instruments and their interaction to estimate Equation 19 in changes. We present the estimation results in Panel A of Table 3 and we find an estimate of $\sigma_{N}=0.2 .^{11}$ Conditional on this estimate of $\hat{\sigma}_{N}$, we can infer local amenities as a structural residual

\footnotetext{
${ }^{10}$ To see this, recall the definition of expected value functions in Equation 5 or Equation OA.2 and note that average CZ-utilities relate to county-utilities through: $u_{m}^{e k} \equiv \log \left[\sum_{n \in \mathbb{N}_{m}} \exp \left(x_{n}^{e k}\right)\right]$.

${ }^{11}$ This value is comparable to the literature. Diamond (2016) finds, for example, a value of 0.24 for lowskill workers and 0.18 for high-skill workers for moves across MSAs using the same data sources and the same definitions of low- and high-skill.
} 
from Equation (19).

TABle 3: Estimation OF MODEL PARAMETERS

\begin{tabular}{|c|c|c|}
\hline Variable Name & Coefficient & $\begin{array}{l}\text { Implied } \\
\text { Parameter }\end{array}$ \\
\hline \multicolumn{3}{|c|}{ Panel A: GMM Estimation of Equation 19} \\
\hline Change in Real Income $\left(\Delta I_{n}^{e 0}\right)$ & $\begin{array}{l}5.248^{* *} \\
(2.569)\end{array}$ & $\sigma_{N}=0.19$ \\
\hline Observations & 1,142 & \\
\hline \multicolumn{3}{|c|}{ Panel B: OLS Estimation of Equation 20} \\
\hline Amenity $\left(a_{n}^{e}\right)$ & $\begin{array}{l}0.784^{* * *} \\
(0.005)\end{array}$ & $\theta=0.78$ \\
\hline Value of Low-Skill Young Adult $(R(m, l))$ & $\begin{array}{l}0.389^{* * *} \\
(0.012)\end{array}$ & $\beta=0.39$ \\
\hline Probability of Staying Low-Skill $(\operatorname{Pr}(l \mid n, e))$ & $\begin{array}{c}-0.085^{* * *} \\
(0.016)\end{array}$ & $\sigma_{E}=0.043$ \\
\hline Observations & 5,744 & \\
\hline R-Squared & 0.905 & \\
\hline
\end{tabular}

Notes: Standard errors in parentheses ${ }^{* * *} \mathrm{p}<0.01,{ }^{* *} \mathrm{p}<0.05,{ }^{*} \mathrm{p}<0.1$. This table presents the results from the second step of our estimation, which decomposes types' countyutilities into the preference weights that each type places on different regional characteristics. Panel A estimates Equation 19 in changes via GMM. The dependent variable is the change in non-parents' county-utility between 2000 and 2010. We pool data from low- and high-skill non-parents and include education fixed effects. We instrument for changes in locations' real income with Bartik-like labor demand shocks, housing supply elasticities, and their interaction. Data availability of housing supply elasticities reduce our sample size. We restrict the sample to individuals between ages 25 and 64 years, which is possible in the 2000 and 2010 data. Panel A shows results where variables are constructed from individual-level data. We estimate the same GMM specification with variables constructed from household-level data and obtain a coefficient of $4.813^{* *}$ (2.248). We use $\sigma_{N}=1 / 5=0.2$ as the middle value between these two estimates. Panel B estimates Equation 20 by OLS. The dependent variable is parents' county-utility. We pool data from low- and high-skill parents, include education fixed effects, and weigh counties by their population size. We restrict the sample to individuals between ages 35 and 44 years, which is possible only in the 2010 data. When causal effects of counties on local college-attendance probabilities are missing or out of the $(0,1)$ bound, we use data on local college-attendance probabilities instead. We obtain both data moments from Chetty and Hendren (2018b).

To identify the remaining parameters $\left(\beta, \sigma_{E}\right)$, we use parents' county-utilities and make the following identifying assumption: 
Assumption 2. Local residential amenities differ between education types, but not between parents and non-parents, so that $a_{n}^{e k}=a_{n}^{e}$.

We write parents' county-utilities as:

$$
x_{n}^{e 1}-\frac{1}{\sigma_{N}} I_{n}^{e 1}=\theta^{e 1} a_{n}^{e}+\beta o(e, n)=\theta^{e 1} a_{n}^{e}+\beta\left[\frac{1}{\sigma_{N}} R(m, l)-\frac{\sigma_{E}}{\sigma_{N}} \log (\operatorname{Pr}(l \mid n, e))\right],
$$

where we allow parents to place a different weight on amenities than non-parents, which we denote by $\theta^{e 1}$. We express local child opportunity values $o(n, e)$ as a function of local continuation values $R(m, l)$ and local education probabilities $\operatorname{Pr}(l \mid n, e)$. All regional characteristics in Equation (20) are known from the data or previous estimates. ${ }^{12} \mathrm{We}$ can therefore estimate the equation by OLS. Assumption 2 allows us to explicitly include the amenity estimates from non-parents in the regression. According to our model, these amenities absorb all unobserved variation (i.e., the entire regression residual) which could otherwise bias our estimation. Intuitively, we use county-utilities of non-parents to identify the general attractiveness (i.e., unobserved amenities) of locations that is independent of local child opportunity values. We then use differences in county-utilities between parents and non-parents to identify parent-specific valuations. The value that parents place on child opportunity values identifies altruism $\beta$. The value they place on local education probabilities compared to local continuation values identifies the dispersion in education taste shocks $\sigma_{E}$. Restricting amenities to be the same for parents and non-parents is necessary to relate differences in parents' residential choices to local child opportunity values. The model provides a good fit of the data despite this restriction and the OLS regression of Equation (20) has an R-squared of 0.91. To estimate the OLS regression, we further have to make assumptions about parents' expectations over their children's continuation values as young adults $R_{t+1}(m, l)$. We assume that parents are naive and expect local values to remain the same in the next generation, so that $R_{t}(m, e)=R_{t+1}(m, e)$. We present the regression results in Panel B of Table 3. We find that parents place a weight of $\theta^{1}=0.78$ on amenities, compared to a value of 1 for non-parents. For the dispersion of education taste shocks we find a value of $\sigma_{E}=0.043$ and for altruism $\beta=0.39 .{ }^{13}$

\footnotetext{
${ }^{12}$ In particular, we have measures of county-utilities $\hat{x}_{n}^{\text {ek }}$ from step 1, real disposable income $\hat{I}_{n}^{e k}$ from the data and calibrated parameters, the dispersion of location taste shocks $\hat{\sigma}_{N}$ from step 2, amenities $\hat{a}_{n}^{e}$ from step 2, education probabilities $\operatorname{Pr}(l \mid n, e)$ from the data, and expected continuation values $\hat{R}(m, l)$ from step 1 and data on fertility probabilities.

${ }^{13}$ Our estimate of altruism is comparable to the literature. Daruich (2018) finds, for example, an estimate of 0.475 , while Abbott et al. (2019) finds parameters of 0.518 for males and 0.470 for females. Compared to these papers, we do not model children's utility and consumption during childhood, so our altruism parameter only captures parental preferences over their children's utility during adulthood. This could explain why our estimates are slightly lower. It is also possible that parents have imperfect information about neighborhoods' effects on their children's future utility, which would bias our altruism estimate downward.
} 


\begin{tabular}{lcl}
\hline $\begin{array}{l}\text { Regional Characteristic } \\
\text { Productivity and }\end{array}$ & Symbol & Description of Identification \\
$\begin{array}{l}\text { Skill Intensity } \\
\text { Housing Supply }\end{array}$ & $\mathcal{Z}_{m}, \mathcal{S}_{m}^{e}$ & $\begin{array}{l}\text { Labor market clearing and data on local } \\
\text { wages and labor supply by skill type. }\end{array}$ \\
Amenity & $\mathcal{H}_{n}$ & $\begin{array}{l}\text { Rental market clearing and data on local } \\
\text { rents and housing expenditure. }\end{array}$ \\
$\begin{array}{l}\text { Exog. Component of } \\
\text { Education Quality }\end{array}$ & $a_{n}^{e} \equiv \mathcal{A}_{n}^{e} / \sigma_{N}$ & $\begin{array}{l}\text { Non-parents' county-utilities and data on } \\
\text { local wages and rents. } \\
\text { Data on local education choices, estimated } \\
\text { education returns, and school funding. }\end{array}$ \\
\hline
\end{tabular}

Notes: This table summarizes how we infer regional characteristics as structural residuals by fitting model predictions to regional data moments. This approach follows the Quantitative Spatial Economics (QSE) literature.

\subsection{Inferring Regional Characteristics as Structural Residuals}

We infer regional characteristics as structural residuals to fit model predictions to regional data moments. This approach follows the Quantitative Spatial Economics literature, reviewed in Redding and Rossi-Hansberg (2017). To infer the exogenous component of local education quality $\mathcal{K}_{n}^{e}$-which is at the heart of our analysis and a novel ingredient in the spatial literature-we rearrange educational choice probabilities (cf. Equation 12) in the following way:

$$
\mathcal{K}_{n}^{e}=R(m, h)-R(m, l)+\gamma^{e} \log \left(f_{n}\right)-\sigma_{E} \log \left(\frac{\operatorname{Pr}(h \mid n, e)}{1-\operatorname{Pr}(h \mid n, e)}\right) .
$$

We can compute exogenous education quality from this equation because all terms on the right-hand side of the equation (i.e., education returns, school funding, and educational choice probabilities) are known from the data or previous estimates.

Amenities for each education type are identified from the residential choices of nonparents. These residential choices are invariant to an additive increase or decrease in utility across all locations, so amenities are identified only up to constant of normalization. We can normalize amenities for each skill type without loss of generality because the residential choices of parents as well as children's education choices are also invariant to amenity levels (as we show in Online Appendix C). Normalizing amenity levels for each skill type additively shifts value function levels and therefore the level of education returns. To fit observed education outcomes, our model offsets the shift in education returns by inversely adjusting the level of exogenous local education quality $\mathcal{K}_{n}^{e}$ (cf. Equation 21). 
The level of skill-specific amenities $a_{n}^{e}$ and the level of exogenous education quality $\mathcal{K}_{n}^{e}$ are therefore jointly, but not separately, identified.

Table 4 describes how we infer the remaining regional characteristics by following the Quantitative Spatial Economics literature.

\section{Decomposition and Policy Counterfactuals}

We now use the estimated model for our counterfactual analysis. First, we decompose the geographic variation in education outcomes into variation due to differences in education quality versus returns to education. Second, we study a counterfactual school funding reform, which equalizes funding across students. We analyze the effects of this reform on education outcomes, intergenerational mobility, and child opportunity values in the aggregate and across locations. In Appendix A, we further analyze a rent subsidy program as an alternative policy to improve social mobility and equality of opportunity. In all counterfactuals, we evaluate the long-run effects of policies by comparing the steady states of a baseline economy and counterfactual economies. We first solve for the baseline steady state because our estimation interprets the data as a transitional period. To solve for the baseline steady state, we fix regional characteristics, tax rates, and school funding allocation rules at their estimated values.

\subsection{Decomposing the Geographic Variation in Education Outcomes}

A key equation of our model links children's education outcomes to local education returns and education quality (cf. Equation 7):

$$
\underbrace{\log \left(\frac{\operatorname{Pr}(h \mid n, e)}{\operatorname{Pr}(l \mid n, e)}\right)}_{\text {College Odds } \equiv \hat{E}_{n}^{e}}=\underbrace{\frac{1}{\sigma_{E}}(R(m, h)-R(m, l))}_{\text {Education Return } \equiv \hat{R}_{m}}+\underbrace{\frac{1}{\sigma_{E}} \mathcal{Q}_{n}^{e}}_{\text {Education Quality } \equiv \hat{\mathcal{Q}}_{n}^{e}} .
$$

To study the importance of these two factors in explaining the large variation in education outcomes across locations, we implement the following variance decomposition:

$$
\operatorname{var}\left(\hat{E}_{n}^{e}\right)=\operatorname{var}\left(\hat{R}_{m}\right)+\operatorname{var}\left(\hat{\mathcal{Q}}_{n}^{e}\right)+2 \operatorname{covar}\left(\hat{R}_{m}, \hat{\mathcal{Q}}_{n}^{e}\right),
$$

where we denote the local odds of attending college by $\hat{E}_{n}^{e}$, local education returns by $\hat{R}_{m}$, and local education quality by $\hat{\mathcal{Q}}_{n}^{e}$.

Rows 1 and 2 of Table 5 present this decomposition for the baseline steady state, separately for children from low- and high-skill families. Education quality and education 


\section{TABLE 5: DECOMPOSING THE GEOGRAPHIC VARIATION \\ IN EDUCATION OUTCOMES}

\begin{tabular}{lcccccc}
\hline & & \multicolumn{3}{c}{ Variances } & & Covariance \\
\cline { 3 - 4 } & $\begin{array}{c}\text { Parental } \\
\text { Skill }\end{array}$ & $\begin{array}{c}\text { College } \\
\text { Odds } \\
\left(\hat{E}_{n}^{e}\right)\end{array}$ & $\begin{array}{c}\text { Education } \\
\text { Returns } \\
\left(\hat{R}_{m}\right)\end{array}$ & $\begin{array}{c}\text { Education } \\
\text { Quality } \\
\left(\hat{\mathcal{Q}}_{n}^{e}\right)\end{array}$ & $\begin{array}{c}\text { Education } \\
\text { Return \& Quality } \\
\left(\hat{R}_{m}, \hat{\mathcal{Q}}_{n}^{e}\right)\end{array}$ \\
\hline Baseline & Low & 0.84 & 4.52 & 5.19 & -4.44 \\
Steady State & High & 0.96 & 4.62 & 6.03 & -4.85 \\
Equalized & Low & 0.23 & 0.23 & 0 & 0 \\
Education Quality & High & 0.20 & 0.20 & 0 & 0 \\
Equalized Expected & Low & 5.93 & 0 & 5.93 & 0 \\
Education Returns & High & 4.24 & 0 & 4.24 & 0 \\
\hline
\end{tabular}

Notes: This table decomposes the geographic variation in education outcomes into variation due to differences in local education quality versus local education returns. Columns present the "simple" variance decomposition for a given steady state of the general equilibrium model. Rows present the baseline steady state (rows 1 and 2) and then the full decomposition in general equilibrium, where we first equalize education quality (rows 3 and 4) and then education returns (rows 5 and 6), solving each time for the new steady state of our model. All terms are population-weighted.

returns vary substantially across locations. Their covariance is negative so childhood locations with lower education quality have on average higher education returns. A possible explanation for the negative covariance could be that low education quality makes it hard for the local population to become educated, which lowers local skill supply and increases skill premia and education returns.

We then perform a model-based decomposition that accounts for interactions between education quality and education returns in general equilibrium. In two separate counterfactuals, we solve for the new steady state by first equalizing education quality and then education returns across locations, respectively by setting them to their average value.

Rows 3 and 4 of Table 5 show that an equalization of education quality across locations substantially reduces the geographic variation in education outcomes. The only driver of this variation now is variation in local education returns. Variation in education returns itself decreases substantially because locations with higher initial education returns had lower initial education quality, i.e., these two objects covary negatively in the baseline. Equalizing education quality therefore improves it in locations with initially higher education returns, which increases local education outcomes and skill supply and therefore decreases local skill premia. The opposite happens in locations with low initial education returns. This mechanism drives skill premia and education returns to become more similar across locations. This endogenous response of local education returns amplifies the 
direct effect of equalizing education quality, leading to a substantial drop in spatial differences in education outcomes. These results hold for children from low- and high-skill families.

Rows 5 and 6 of Table 5 show that an equalization of education returns instead increases the geographic variation in education outcomes. The only driver of this variation now is variation in local education quality. Local education quality can adjust endogenously through changes in local school funding. However, this channel does not lower the variation in education quality, which remains large and even increases slightly for children of low-skill families. The geographic variation in education outcomes increases because local education quality and local education returns are negatively correlated in the baseline. Equalizing education returns therefore reduces them in locations where education quality is low, which further deteriorates education outcomes in these low-performing locations.

These results emphasize the importance of local education quality to explain spatial differences in education outcomes. We now study the role of local school funding as an important and policy-relevant component of local education quality.

\subsection{Effects of Equalizing School Funding}

We now use our model to study a budget-neutral school funding reform, which allocates funds equally across students and raises all revenues through federal wage taxes. We analyze the effects of this reform on education outcomes, intergenerational mobility, and child opportunity values.

\subsubsection{Equalizing School Funding and the Geographic Variation in Education Out- comes}

We study the effects of equalizing school funding on the geographic variation in education outcomes by extending the variance decomposition of Equation 22 in the following way:

$$
\begin{aligned}
\operatorname{var}\left(\hat{E}_{n}^{e}\right)= & \operatorname{var}\left(\hat{R}_{m}\right)+\operatorname{var}\left(\hat{\mathcal{K}}_{n}^{e}\right)+\operatorname{var}\left(\hat{f}_{n}\right) \\
& +\underbrace{2 \operatorname{covar}\left(\hat{R}_{m}, \hat{\mathcal{K}}_{n}^{e}\right)}_{\text {in baseline (-) }}+\underbrace{2 \operatorname{covar}\left(\hat{R}_{m}, \hat{f_{n}}\right)}_{\text {in baseline (+) }}+\underbrace{2 \operatorname{covar}\left(\hat{\mathcal{K}}_{n}^{e}, \hat{f}_{n}\right)}_{\text {in baseline }(-)} .
\end{aligned}
$$

Local education quality is now expressed as a function of endogenous local per student school funding and an exogenous local component. We denote terms related to local odds of attending college by $\hat{E}_{n}^{e}$, education returns by $\hat{R}_{m}$, the exogenous component of 


\section{TABLE 6: EFFECTS OF EQUALIZING SCHOOL FUNDING ON THE GEOGRAPHIC VARIATION IN EDUCATION OUTCOMES}

\begin{tabular}{|c|c|c|c|c|c|c|c|c|}
\hline & \multirow[b]{2}{*}{$\begin{array}{c}\text { Parental } \\
\text { Skill }\end{array}$} & \multicolumn{4}{|c|}{ Variances } & \multicolumn{3}{|c|}{ Covariances } \\
\hline & & $\begin{array}{c}\text { College } \\
\text { Odds } \\
\left(\hat{E}_{n}^{e}\right)\end{array}$ & $\begin{array}{c}\text { Education } \\
\text { Return } \\
\left(\hat{R}_{m}\right)\end{array}$ & $\begin{array}{c}\text { Education } \\
\text { Quality } \\
\left(\hat{\mathcal{K}}_{n}^{e}\right)\end{array}$ & $\begin{array}{c}\text { Education } \\
\text { Funding } \\
\left(\hat{f}_{n}\right)\end{array}$ & $\begin{array}{c}\text { Return \& } \\
\text { Quality } \\
\left(\hat{R}_{m}, \hat{\mathcal{K}}_{n}^{e}\right)\end{array}$ & $\begin{array}{c}\text { Return \& } \\
\text { Funding } \\
\left(\hat{R}_{m}, \hat{f}_{n}\right)\end{array}$ & $\begin{array}{c}\text { Quality \& } \\
\text { Funding } \\
\left(\hat{\mathcal{K}}_{n}^{e}, \hat{f}_{n}\right)\end{array}$ \\
\hline Baseline & Low & 0.84 & 4.52 & 6.11 & 0.37 & -4.76 & 0.32 & -0.64 \\
\hline Steady State & High & 0.96 & 4.62 & 6.95 & 0.33 & -5.13 & 0.28 & -0.62 \\
\hline Equal Funding & Low & 1.11 & 4.52 & 6.11 & 0 & -4.76 & 0 & 0 \\
\hline Direct Effect & High & 1.31 & 4.62 & 6.95 & 0 & -5.13 & 0 & 0 \\
\hline Equal Funding & Low & 0.89 & 5.25 & 6.12 & 0 & -5.24 & 0 & 0 \\
\hline GE Effect & High & 1.01 & 5.37 & 6.98 & 0 & -5.67 & 0 & 0 \\
\hline
\end{tabular}

Notes: This table documents the effects of equalizing school funding on the geographic variation in education outcomes. Columns present the "simple" variance decomposition of local education outcomes $\hat{E}_{n}^{e}$ into parts due to local education returns $\hat{R}_{m}$, local exogenous education quality $\hat{\mathcal{K}}_{n}^{e}$, and local school funding $\hat{f}_{n}$ for a given steady state. Rows present the baseline steady state (rows 1 and 2 ) and then the effects of equalizing school funding on the geographic variation in education outcomes. We first present the direct effects where all objects except education choices are held constant (rows 3 and 4) and then the full general equilibrium effects where all margins of our model adjust (rows 5 and 6). All terms are population-weighted.

education quality by $\hat{\mathcal{K}}_{n}^{e}$, and school funding by $\hat{f}_{n}$. We first consider the direct effects of equalizing school funding by holding all model objects besides funding and education choices constant. ${ }^{14}$ We then implement the full general equilibrium (GE) effects where all margins adjust endogenously. This approach allows us to evaluate the importance of endogenous responses to the reform.

Rows 1 and 2 of Table 6 present the variance decomposition for the baseline steady state. Education returns and exogenous education quality vary substantially across locations, while school funding has a smaller variance. Local exogenous education quality and education returns have a negative covariance. Local school funding covaries positively with education returns but negatively with exogenous education quality. School funding is therefore on average higher in locations that face other education frictions.

The direct effects of equalizing school funding holding all else constant substantially increase the geographic variation in education outcomes (Rows 3-4 of Table 6). Locations with initially higher school funding have on average lower exogenous education quality since these two objects negatively covary in the baseline. Equalizing school funding therefore reduces funds in locations where exogenous education quality is low, further deteriorating the low education quality. The opposite applies to locations with high exogenous education quality that now receive more school funding. Spatial differences in

\footnotetext{
${ }^{14}$ In particular, we fix local population stocks, education returns, rents, wages, and continuation values. This counterfactual can be thought of as a one-period change in school funding that is announced after families have made their residential choices, but before they have chosen their children's education.
} 
education outcomes therefore increase, which holds for children from low- and high-skill families.

Equalizing school funding in general equilibrium again increases the geographic variation in education outcomes (Rows 5-6) but much less than the direct effects. In general equilibrium, skill premia now increase in locations where school funding cuts decrease education outcomes and skill supply. Higher skill premia create incentives for children to get educated, which mitigates the direct effects of funding cuts on education outcomes. The opposite applies to locations where school funding increases. General equilibrium responses and the interactions between the funding changes and regional characteristics are therefore important to evaluate the reform's long-run effects.

\subsubsection{Equalizing School Funding and Children's Outcomes by Family Background}

Education Outcomes by Family Background. We now document the effects of equalizing school funding on social mobility by comparing changes in children's education outcomes between low- and high-skill families. In the baseline, average per student school funding is higher for children from high-skill families because they live on average in better-funded counties. ${ }^{15}$ Equalizing school funding increases average per student funding by 1.8 percent for low-skill families and reduces it by 1.4 percent for high-skill families. Table 7 shows the reform's effect on the average probability of attending college for children from low- and high-skill families, where we take population-weighted averages across all locations. We again consider the direct effects of equalizing school funding (where only education choices adjust) and the full general equilibrium case (where all margins adjust). The direct effects increase children's probability of attending college by 3.15 p.p. for low-skill families. However, these effects are mitigated to a 0.57 p.p. increase in general equilibrium. For high-skill families, direct effects decrease children's probability of attending college by 0.47 p.p., which is similar in general equilibrium with a 0.33 p.p. decrease.

Mechanisms. We now investigate how school funding, education returns, and exogenous education quality contribute to the effects in general equilibrium (Panels B-D of Table 7). School funding changes have a net positive effect on children's education outcomes for low-skill families and a negative effect for high-skill families (cf. Panel B and directeffect scenario). Returns to education and skill premia decrease on average due to the reform, which lowers children's incentives to get educated for low- and high-skill families (Panel C). Differences in exogenous education quality contribute negatively to changes

\footnotetext{
${ }^{15}$ We assume that school funding is equally available to all students in the same county.
} 
TABLE 7: EFFECTS OF EQUALIZING SCHOOL FUNDING ON EDUCATION OUTCOMES BY FAMILY BACKGROUND

\begin{tabular}{cccc}
\hline Parental Skill & Direct Effect & $\begin{array}{c}\text { General } \\
\text { Equilibrium }\end{array}$ & Fixed Wages \\
\hline Panel A: Probability of Attending College (p.p. change) & 0.11 & 0.793 \\
\hline All & 1.15 & 0.57 & -0.75 \\
Low & 3.15 & -0.33 & 1.51 \\
High & -0.47 & $(+)$ & $(+)$ \\
\hline \multicolumn{4}{c}{ Panel B: Effect from School Funding } \\
\hline High & $(+)$ & $(-)$ & $(-)$ \\
\hline Low & Panel C: Effect from Education Returns & $(-)$ \\
\hline High & None & $(-)$ & $(-)$ \\
\hline Panel D: Effect from Exogenous Education Quality \\
\hline Low
\end{tabular}

Notes: Panel A of this table documents the effects of equalizing school funding on the probability of attending college for children from low- and high-skill families. Numbers in Panel A represent percentage point changes in population-weighted averages relative to the baseline steady state. Column 1 shows the direct effects of equalizing school funding where all objects except education choices are held constant. Column 2 documents the full general equilibrium effects where all margins of our model adjust. Column 3 allows all margins to adjust except local wages, which are held constant. Panels B-D analyze the mechanisms behind the results by documenting how school funding, education returns, and exogenous education quality contribute to the policy's effects on education outcomes. 
in children's education outcomes for low-skill families and positively for high-skill families (Panel D). Exogenous education quality in each location is constant by definition. It nevertheless matters for changes in education outcomes because children's exposure to locations changes in response to policies. In particular, changes in families' residential and educational choices shift more low-skill (and fewer high-skill) families into locations with lower exogenous education quality compared to the baseline. The shift happens in the following way: First, the equalization of school funding reduces funds in locations where exogenous education quality is low because initial funding is negatively correlated with exogenous education quality. The funding cut reduces education outcomes which increases the share of low-skill families in these low-education-quality locations. Lower skill supply in these locations increases skill premia. These local wage changes mitigate the reduction in the local skill composition by increasing children's incentives to get educated and by changing young adults' residential choices. In particular, the decline in low-skill wages decreases net inflows of low-skill young adults and the rise in high-skill wages increases net inflows of high-skill young adults. Changes in net moving flows therefore weaken the link between children's local education outcomes and adults' local skill supply. Wage changes offset the direct effects of the funding cut only partially, so the equalization of school funding increases the share of low-skill families and decreases the share of high-skill families in locations with low exogenous education quality.

The effects of wage changes and resulting moving flow changes are nevertheless important: If we hold wages constant, we find a much larger shift of low-skill families into locations with low exogenous education quality (Column 3 of Table 7). Remarkably, under constant wages this effect is so strong that children's education outcomes decrease for low-skill families despite an increase in average school funding. Similarly, children's education outcomes increase for high-skill families despite a reduction in average school funding. ${ }^{16}$

Expected Income and Child Opportunities by Family Background. Table 8 shows the effects of equalizing school funding on children's expected income and child opportunity values for low- and high-skill families. We compute children's expected income for each parental education level and childhood location by taking expectations over children's future education level, family type, and moving decision. Equalizing school funding

\footnotetext{
${ }^{16}$ In this counterfactual, local wages and local skill premia are fixed, so changes in average education returns are small and mostly driven by shifts of low- and high-skill families across locations that differ in education returns. School funding and education returns are positively correlated in the baseline (cf. Table 6). Equalizing school funding therefore reduces funds in locations where initial education returns are high. The reform therefore shifts low-skill (high-skill) families toward locations with higher (lower) education returns compared to the baseline.
} 


\begin{tabular}{lcc}
\hline & Parental Skill & Changes from Baseline \\
\hline Expected & Low & $0.32 \%$ \\
Income & High & $-0.35 \%$ \\
\hline Child Opportunity & Low & $0.42 \%$ \\
Value & High & $0.10 \%$ \\
\hline
\end{tabular}

Notes: This table documents the effects of equalizing school funding on expected income and child opportunity values (i.e., expected utility at birth) for children from low- and high-skill families. All numbers are percentage changes in population-weighted averages relative to the baseline steady state.

increases expected income by 0.3 percent for children from low-skill families. These children are now more likely to become high-skill and their average wage is higher if they remain low-skill. Expected income for children from high-skill families decreases by 0.35 percent because they are less likely to become high-skill and their average wage is lower if they become high-skill. Child opportunity values-the expected lifetime utility of children at birth-increases for children from low- and high-skilled families, albeit more for low-skill families with an increase of 0.4 percent compared to 0.1 percent for high-skill families. Expected utility at birth increases for children from high-skill families (despite lower expected income) for two reasons. First, utility is now higher for children who remain low-skill. Lower inequality in the economy therefore serves as an insurance against the possibility of receiving low education taste shocks. Second, more high-skill families now live in locations with better education quality, which lowers their children's utility cost of accumulating skills.

Discussion and Summary of Results. Our decomposition shows that equalizing education quality across locations substantially reduces the geographic variation in education outcomes because effects are further amplified through an endogenous decrease in the geographic variation in education returns. However, equalizing education returns or school funding increases the geographic variation in education outcomes by further deteriorating outcomes in locations with low exogenous education quality and by shifting more low-skill families into these locations.

Comparing effects by family background, we find that equalizing school funding has large direct effects on children's education outcomes for low-skill families. Effects are substantially reduced in general equilibrium because of a decrease in average education 
returns and a shift of low-skill families into locations with lower exogenous education quality. For high-skill families, the equalization of school funding has negative but small effects on their children's education outcomes. Direct effects and full general equilibrium effects are similar for high-skill families because lower returns to education are offset by a shift of high-skill families toward locations with better exogenous education quality. Overall, the equalization of school funding has positive but modest effects on social mobility. Our results and the analysis of the mechanisms emphasize the importance of accounting for interactions between local education quality, local labor markets, and families' education and residential choices when evaluating the long-run effects of education policies. Appendix A shows that our results are robust to the inclusion of peer effects in education and to different sample selections.

\section{CONCLUSION}

Neighborhoods in the United States shape children's educational and economic opportunities, putting at risk the equality of opportunity at the heart of the American dream. Recent work by Chetty and Hendren (2018b) provides the first estimates of the causal effects of each US county on its children's education and economic outcomes. They document large differences in opportunities across counties which create an urgent need to understand the determinants behind these effects and formulate policies that promote equality of opportunity.

Our paper advances these objectives by developing a quantitative spatial equilibrium model that generates neighborhood effects through local education quality and local labor market access. Our framework bridges the gap between an early theoretical literature and recent empirical work. To estimate our model, we use the county-level neighborhood effects from Chetty and Hendren (2018b), elasticity estimates from the applied micro literature, and data on regional outcomes and characteristics from multiple census data sets.

Our framework can be used to analyze education policies in spatial equilibrium taking into account how local education quality and education returns interact and respond to policy. In this paper, we focus on an equalization of school funding: an intensively debated policy. We find large differences between direct and general equilibrium effects highlighting the importance of accounting for interactions between local markets, local education quality, and families' educational and residential choices.

Our model can be extended to study many applications and policy questions for which local education outcomes are important. Future research should extend the model to study 
additional endogenous local factors that characterize local labor markets and local education quality. A key challenge to the inclusion of additional endogenous factors is the identification of the structural parameters that measure the direct effect of each local factor on education outcomes. The estimation of such micro-elasticities and the inclusion of additional endogenous determinants into our framework are promising future research applications. Of particular interest is the role of peers in shaping children's education outcomes. We show in the Appendix how peer effects can be integrated into our framework in a straightforward way but leave a thorough analysis for future research.

Our unified framework of local human capital production, local labor markets, and costly migration can be further used to study the persistence of regional inequality, rural-urban wage gaps, and low migration rates in advanced or developing countries. Other interesting applications could study the effects of policies on local development by targeting either local skill supply (e.g., investing in education or attracting skilled workers) or local skill demand (e.g., subsidizing companies or creating industrial zones).

\section{REFERENCES}

Aввотt, B., G. Gallipoli, C. Meghir, And G. L. Violante (2019): “Education Policy and Intergenerational Transfers in Equilibrium," Journal of Political Economy, 126 (6), 2569-2624.

Agostinelli, F. (2018): “Investing in Children's Skills: An Equilibrium Analysis of Social Interactions and Parental Investments," Unpublished Manuscript, University of Pennsylvania.

AltONJI, J. AND R. MANSFIELD (2018): “Estimating Group Effects Using Averages of Observables to Control for Sorting on Unobservables: School and Neighborhood Effects," The American Economic Review, 108(10), 2902-2946.

ARTUÇ, E. AND J. MCLAREN (2015): “Trade policy and wage inequality: A structural analysis with occupational and sectoral mobility," Journal of International Economics, 97(2), 278-294.

Autor, D. H., L. F. KATZ, AND A. B. KRUeger (1998): “Computing Inequality: Have Computers Changed the Labor Market?" Quarterly Journal of Economics, 113 (4), 11691213. 
BARTIK, T. J. (1991): “Who Benefits from State and Local Economic Development Policies?" Kalamazoo, MI: W. E. Upjohn Institute for Employment Research.

BAyer, P., F. Ferreira, AND R. McMillan (2007): “A Unified Framework for Measuring Preferences for Schools and Neighborhoods," Journal of Political Economy, 115 (4), 588-638.

Benabou, R. (1993): "Workings of a City: Location, Education, and Production," The Quarterly Journal of Economics, 108 (3), 619-652.

- (1996): "Heterogeneity, Stratification, and Growth: Macroeconomic Implications of Community Structure and School Finance," The American Economic Review, 86 (3), 584-609.

Bergman, P., R. Chetty, S. Deluca, N. Hendren, L. F. Katz, and C. Palmer (2020): “Creating Moves to Opportunity: Experimental Evidence on Barriers to Neighborhood Choice," NBER Working Paper, No. 26164.

Berry, C. R. And E. L. Glaeser (2005): “The Divergence of Human Capital Levels across Cities," Papers in Regional Science, 84 (3), 407-444.

Berry, S., J. LeVinsohn, And A. Pakes (2004): “Differentiated Products Demand Systems from a Combination of Micro and Macro Data: The New Car Market," Journal of Political Economy, 112 (1), 68-105.

BIASI, B. (2019): “School Finance Equalization Increases Intergenerational Mobility: Evidence from a Simulated Instruments Approach," NBER Working Paper, No. 25600.

Bilal, A. And E. Rossi-Hansberg (2018): “Location as an Asset," NBER Working Paper, No. 24867.

Bryan, G. AND M. Morten (2019): “The Aggregate Productivity Effects of Internal Migration: Evidence from Indonesia," Journal of Political Economy, 127 (5), 2229-2268.

CAliendo, L., M. Dvorkin, And F. PARro (2019): “Trade and Labor Market Dynamics: General Equilibrium Analysis of the China Trade Shock," Econometrica, 87 (3), 714-835.

CARrell, S. E., M. Hoekstra, And E. KUKA (2018): “The Long-Run Effects of Disruptive Peers," The American Economic Review, 108(11), 3377-3415. 
CHETTY, R. AND N. HENDREN (2018a): “The Impacts of Neighborhoods on Intergenerational Mobility I: Childhood Exposure Effects*," The Quarterly Journal of Economics, 133, $1107-1162$.

(2018b): "The Impacts of Neighborhoods on Intergenerational Mobility II: CountyLevel Estimates*," The Quarterly Journal of Economics, 133, 1163-1228.

Chetty, R., N. Hendren, AND L. F. Katz (2016): “The Effects of Exposure to Better Neighborhoods on Children: New Evidence from the Moving to Opportunity Experiment," The American Economic Review, 129 (4), 1553-1623.

Chetty, R., N. Hendren, P. Kline, AND E. SAez (2014): “Where is the land of Opportunity? The Geography of Intergenational Mobility in the United States," The Quarterly Journal of Economics, 129 (4), 1553-1623.

Ciccone, A. AND G. Peri (2005): “Long-Run Substitutability between More and Less Educated Workers: Evidence from U.S. States 1950-1990," Review of Economics and Statistics, 87(4), 652-663.

Cunha, F., J. J. Heckman, And S. M. Schennach (2010): “Estimating the Technology of Cognitive and Noncognitive Skill Formation," Econometrica, 78 (3), 883-931.

DARUICH, D. (2018): “The Macroeconomic Consequences of Early Childhood Development Policies," FRB St. Louis Working Paper, No. 2018-29.

DiAMOND, R. (2016): “The Determinants and Welfare Implications of US Workers' Diverging Location Choices by Skill: 1980-2000," The American Economic Review, 106 (3), 479-524.

Durlauf, S. N. (1996a): “Neighborhood feedbacks, endogenous stratification, and income inequality," Dynamic Disequilibrium Modelling: Proceedings of the Ninth International Symposium on Economic Theory and Econometrics, W. Barnett, G. Gandolfo, and C. Hillinger, eds.

(1996b): “A Theory of Persistent Income Inequality," Journal of Economic Growth, 1 (1), 75-93.

_ (2004): "Neighborhood Effects," Handbook of Regional and Urban Economics, 4, 21732242.

Durlauf, S. N. AND A. Seshadri (2017): “Understanding the Great Gatsby Curve," NBER Macroeconomics Annual, 32, 333-393. 
EeckHout, J., R. Pinheiro, AND K. Schmidheiny (2014): “Spatial sorting," Journal of Political Economy, 122 (3), 554-620.

Fernandez, R. AND R. Rogerson (1996): “Income Distribution, Communities, and the Quality of Public Education," The Quarterly Journal of Economics, 111 (1), 135-164.

_ (1997): "Keeping People Out: Income Distribution, Zoning, and the Quality of Public Education," International Economic Review, 38 (1), 23-42.

- (1998): "Public Education and Income Distribution: A Dynamic Quantitative Evaluation of Education-Finance Reform," The American Economic Review, 88 (4), 813-833.

Fogli, A. AND V. GUERRIERI (2019): "The End of the American Dream? Inequality and Segregation in US cities," NBER Working Paper, No. 26143.

Fryer, R. G. AND L. F. KATZ (2013): “Achieving Escape Velocity: Neighborhood and School Interventions to Reduce Persistent Inequality," The American Economic Review: Papers \& Proceedings, 103 (3), 232-237.

Gyourko, J., A. SAIZ, AND A. Summers (2008): “A New Measure of the Local Regulatory Environment for Housing Markets: The Wharton Residential Land Use Regulatory Index," Urban Studies, 45 (3), 693-729.

Heckman, J. J., L. LOChNer, AND C. TABer (1998): “Explaining Rising Wage Inequality: Explorations with a Dynamic General Equilibrium Model of Labor Earnings with Heterogeneous Agents," Review of Economic Dynamics, 1(1), 1-58.

JaCKson, C. K., R. C. Johnson, AND C. Persico (2016): “The Effects of School Spending on Educational and Economic Outcomes: Evidence from School Finance Reforms," The Quarterly Journal of Economics, 131 (1), 157-218.

KATZ, L. F., J. R. KLING, AND J. B. Liebman (2001): “Moving to Opportunity in Boston: Early Results of a Randomized Mobility Experiment," The Quarterly Journal of Economics, 116(2), 607-54.

KatZ, L. F. AND K. M. Murphy (1992): “Changes in Relative Wages, 1963-1987: Supply and Demand Factors," The Quarterly Journal of Economics, 107 (1), 35-78.

LeE, S. AND J. LiN (2018): “Natural Amenities, Neighbourhood Dynamics, and Persistence in the Spatial Distribution of Income," Review of Economic Studies, 85, 663-694. 
Mogstad, M., J. P. Romano, A. Shaikh, And D. Wilhelm (2020): "Inference for Ranks with Applications to Mobility across Neighborhoods and Academic Achievement across Countries," NBER Working Paper, No. 26883.

Moretti, E. (2013): "Real Wage Inequality," American Economic Journal: Applied Economics, 5(1), 65-103.

Nechyвa, T. J. (2006): “Income and Peer Quality Sorting in Public and Private Schools," Handbook of the Economics of Education, 2 (22), 1327-1368.

Porcher, C. (2019): "Migration with Costly Information," Princeton University Mimeo.

Redding, S. And A. J. Venables (2004): “Economic geography and international inequality," Journal of International Economics, 62 (1), 53-82.

RedDing, S. J. And E. Rossi-HANSberg (2017): “Quantitative Spatial Economics," $A n-$ nual Review of Economics.

Redding, S. J. AND D. M. Sturm (2008): “The Costs of Remoteness: Evidence from German Division and Reunification," The American Economic Review, 98 (5), 1766-97.

Ruggles, S., K. GenadeK, R. Goeken, J. Grover, and M. SobeK (2017): “Integrated Public Use Microdata Series: Version 7.0," Minneapolis: University of Minnesota, 2017. https://doi.org/10.18128/D010.V7.0.

Silva, J. M. C. S. And S. Tenreyro (2006): "The log of Gravity," The Review of Economics and Statistics, 88(4), 641-658.

TOlBeRT, C. M. AND M. Sizer (1996): “US Commuting Zones and Labor Market Areas: A 1990 Update," ERS Staff Paper.

TsIVANIDIS, N. (2018): “Evaluating the Impact of Urban Transit Infrastructure: Evidence from Bogota's TransMilenio," Working Paper.

ZHENG, A. AND J. GRAHAM (2020): "Public Education Inequality and Intergenerational Mobility," SSRN, http://dx.doi.org/10.2139/ssrn.3092714. 


\section{A. Appendix: Additional Results}

In this Appendix, we present two additional exercises. First, we analyze the school funding equalization in an extended version of our model that features peer effects as an additional endogenous component of local education quality. Second, we evaluate rent subsidies to low-skill parents as an alternative policy to increase social mobility by incentivizing them to move to locations with better child opportunity values.

\section{A.1 Peer Effects in Education and Equalizing School Funding}

Peer effects can be an additional important determinant of local education quality. A large literature studies peer effects in education, emphasizing that the presence of high-skill children or families in a school or neighborhood can have positive spillovers on education outcomes of other children (c.f. Benabou (1993), Benabou (1996), Durlauf (1996b), Fogli and Guerrieri (2019), and Agostinelli (2018)). Importantly, the skill composition of local peers can change in response to education policies if they induce low- and high-skill families to move across neighborhoods. In our model, the skill composition of neighborhoods is endogenously determined by families' residential and educational choices. We can therefore incorporate peer effects simply by specifying local education quality as:

$$
\mathcal{Q}_{n}^{e}=\mu^{e} \log \left(\bar{e}_{n}\right)+\gamma^{e} \log \left(f_{n}\right)+\tilde{\mathcal{K}}_{n}^{e},
$$

where $\bar{e}_{n}$ is the local share of high-skill families, $f_{n}$ is local school funding, and $\tilde{\mathcal{K}}_{n}^{e}$ is the exogenous component of local education quality that corresponds to this model specification. The parameters $\mu^{e}$ and $\gamma^{e}$ respectively measure the causal effects of peers and school funding on education quality.

Identifying the strength of peer effects $\mu^{e}$ is challenging and there is no clear consensus on the size of this parameter in the literature. Most empirical studies focus on peer effects in classrooms and not at the neighborhood level. Agostinelli (2018) finds, for example, large peer effects in classrooms that are stronger for children from disadvantaged backgrounds. Fogli and Guerrieri (2019) estimate the strength of local skill spillovers by targeting moments from the causal effect estimates from Chetty and Hendren (2018a). On the other hand, Carrell et al. (2018) find that exposure to disruptive peers has particularly large negative effects on children's future income. Given the wide range of estimates in the literature, we consider three cases with weak $\left(\mu^{e} / \sigma_{E}=\{1.5,1\}\right)$, medium $\left(\mu^{e} / \sigma_{E}=\{2,1.5\}\right)$, and strong $\left(\mu^{e} / \sigma_{E}=\{4,3\}\right)$ peer effects. The first number indicates the parameter for children from low-skill families, the second for high-skill families. Following Agostinelli 
(2018), we assume that peer effects are larger for children from low-skill families.

For each parameter set, we implement the counterfactuals that equalize school funding in the following way: First, we re-estimate the exogenous component of education quality from Equation A.1 to ensure that each extended model fits observed education choices. ${ }^{17}$ Next, we solve for the respective baseline steady state while holding all parameters constant at their estimated values. Finally, we equalize school funding in the same way as in the main part of our paper and we solve for the counterfactual steady state.

Table A.1 presents the differences in probabilities of college attendance and child opportunity values between each of the three counterfactual steady states and the corresponding baseline steady states. For comparability, we include our benchmark results without peer effects. We find that the estimated effects of equalizing school funding are similar with none, weak, medium, or strong peer effects. Despite the similarities in the results, we nevertheless see some differences. For children from low-skill families, we find that peer effects slightly increase effects on education outcomes and child opportunity values. However, these improvements are very small, with increases in children's probability of attending college ranging from 0.57 p.p. without peer effects to 0.65 p.p. with strong peer effects. Results are even more similar for children from high-skill families for whom college-attendance probabilities decrease by 0.33 p.p. without peer effects and by 0.36 p.p. with strong peer effects. The inclusion of peer effects has small effects on the results because the school funding equalization does not substantially change the skill composition in neighborhoods. This is partly due to non-parents, who contribute to local peer effects but whose residential choices do not directly respond to changes in school funding.

\section{A.2 Subsidizing "Moves to Opportunity"}

Many academic studies and policy experiments consider rent subsidies or rent vouchers as tools for improving social mobility and education opportunities for children from disadvantaged backgrounds (e.g., Bergman et al. (2020), Katz et al. (2001), Chetty et al. (2016) and many others). A well-known example is the Moving to Opportunity (MTO) study, which offered housing vouchers to randomly selected families if they moved from high-poverty housing projects to lower-poverty neighborhoods. Katz et al. (2001) found in an initial study that these moves had no significant effects on the earnings and employment rates of adults who accepted the voucher. In a recent study, Chetty et al. (2016)

\footnotetext{
${ }^{17}$ We can re-estimate the exogenous education quality without re-estimating any other model parameters due to the sequential structure of our estimation strategy, in which these regional characteristics are inferred as structural residuals in the last step of the estimation procedure.
} 


\begin{tabular}{|c|c|c|c|c|}
\hline \multirow[b]{2}{*}{ Parental Skill } & \multicolumn{4}{|c|}{ Strength of Peer Effects } \\
\hline & None & Weak & Medium & Strong \\
\hline \multicolumn{5}{|c|}{ Panel A: Probability of Attending College (p.p. change) } \\
\hline Low & 0.57 & 0.60 & 0.61 & 0.65 \\
\hline High & -0.33 & -0.34 & -0.35 & -0.36 \\
\hline \multicolumn{5}{|c|}{ Panel B: Child Opportunity Value (\% change) } \\
\hline Low & 0.42 & 0.44 & 0.45 & 0.48 \\
\hline High & 0.10 & 0.11 & 0.12 & 0.14 \\
\hline
\end{tabular}

Notes: This table shows the effects of equalizing school funding on the probability of attending college and child opportunity values when allowing for peer effects in education. We consider different sets of parameters that imply weak, medium, and strong peer effects. All numbers represent percentage or percentage point changes in population-weighted averages relative to the respective baseline steady state which we recompute for each peer effect level.

estimate the effects of these moves on children's long-run outcomes. They find significant improvements in college attendance and earnings for children who moved to better neighborhoods at young ages. ${ }^{18}$ However, the MTO study offered rent vouchers only to a small number of families, so that the moves did not generate general equilibrium effects. If rent subsidies would instead be implemented as an economy-wide and permanent policy, then widespread moves could affect local skill compositions, local rents, and local wages. We use our model to study the effects of a large-scale rent subsidy program which allows us to account for general equilibrium effects and interactions between local labor market outcomes, local education quality, and families' education and residential choices. Specifically, we consider a policy that reimburses 20 percent of total rent expenditure to low-skill parents conditional on living in locations that are in the top quartile of the baseline distribution of education outcomes. We fund the rent subsidy through a lump-sum tax on all workers. Table A.2 shows that the rent subsidy has moderate effects on education outcomes. Children's probability of attending college increases by 0.35 p.p. for low-skill families and decreases by 0.4 p.p. for high-skill families. Despite the small ef-

\footnotetext{
${ }^{18}$ Our model framework is consistent with these findings. Families in the MTO study moved between close-by neighborhoods so that they stayed in the same labor market. In that case, our model predicts that adults' earnings remain unchanged, but that children's education outcomes and their future income improve if families moved to neighborhoods with better education quality.
} 


\begin{tabular}{lcc}
\hline & Parental Skill & Change from Baseline \\
\hline Probability of & Low & 0.35 p.p. \\
Attending College & High & -0.41 p.p. \\
\hline Child Opportunity & Low & $-0.27 \%$ \\
Value & High & $-0.04 \%$ \\
\hline
\end{tabular}

Notes: This table presents the effects of subsidizing rent of low-skill parents on children's probability of attending college and on average child opportunity values for low- and high-skill families. The rent subsidy is funded through a lump-sum tax and reimburses 20 percent of total rent expenditure to low-skill parents conditional on living in locations with good education outcomes in the baseline. All numbers represent percentage or percentage point changes in population-weighted averages relative to the baseline steady state.

fects, the subsidy successfully increases the share of low-skill parents who live in eligible locations (by approximately 20 percent), so more children from low-skill families have access to high education quality. The subsidy increases rents in eligible locations, which pushes low-skill non-parents and high-skill families out of these locations. Overall, the share of low-skill workers increases in eligible locations, which lowers low-skill wages and raises high-skill wages. Despite the increase in local skill premia, returns to education measured in utils nevertheless decline due to the eligibility rules of the policy. Only low-skill parents are eligible to receive the subsidy, which raises their utility and makes it more attractive for children to remain low-skill. The redistributive nature of the policy therefore has unintended effects which lower children's incentives to become educated for children from low- and high-skill families.

The child opportunity values decrease by 0.27 percent for children from low-skill families and by 0.04 percent for high-skill families. Child opportunity values are children's expected utility at birth where the expectation is taken over all possible future education and family types. The child opportunity values decrease because the subsidy increases the welfare of low-skill parents but decreases it for all other education and family types who are not eligible for the rent subsidy but face higher rents and have to pay the lumpsum tax to fund the subsidy. 


\section{A.3 Robustness of Results to Samples and Imputations}

To test the robustness of our results, we re-compute the decomposition and policy counterfactuals in a variety of different samples. We re-estimate regional characteristics each time by inferring the structural residuals that perfectly fit our model predictions to regional data moments (as described in Section 5.3). We do not re-estimate the structural and time-invariant parameters (cf. Section 5.1 and 5.2). In the main analysis of our paper, we use 2010 data and restrict the sample to workers between 35 and 44 years. ${ }^{19}$ We test the robustness of our results to other sample selections by using data for all workers above 25 years. For this age group, we implement all counterfactuals with data from 1990 and 2010.

We further test the robustness of our results to different county samples. A key data moment for our quantitative analysis are the causal effects of childhood counties on children's education choices which we obtain from Chetty and Hendren (2018b). In the main analysis of our paper, we complement these data with information on local collegeattendance probabilities (also obtained from Chetty and Hendren (2018b)) when causal effect estimates are missing or out of the admissible $(0,1)$ bounds for probabilities. We test whether this imputation affects our results by re-computing all counterfactuals in a smaller county sample for which causal effect estimates are available. In addition, we re-compute all counterfactuals in a sample of counties for which the causal effects are most precisely estimated. In particular, we exclude counties for which standard errors of estimated causal effects lie in the top 25 or top 50 percentiles. This exercise addresses potential concerns about the robustness of the causal effect estimates from Chetty and Hendren (2018b) (as discussed, for example, in Mogstad et al. (2020)).

For all of these different data samples, we find that our results and the underlying mechanisms are qualitatively unchanged and quantitatively very similar. This finding holds for the decomposition and the equalization of school funding.

\footnotetext{
${ }^{19}$ This age group best maps to the timing in our model which assumes that adults move after finishing their education and after knowing whether they have children or not, but before joining the labor market.
} 


\section{ONLINE APPENDIX FOR \\ SAVING THE AMERICAN DREAM? \\ EDUCATION POLICIES IN SPATIAL GENERAL EQUILIBRIUM}

BY FABIAN ECKERT AND TATJANA KLEINEBERG

FOR ONLINE PUBLICATION ONLY 


\section{A. Model Solution And Derivations}

This section provides all equations that characterize the solution of our extended quantitative model (described in Section 4). The equations are closely related to the solution of our core framework (described in Section 3).

Static Choice between Housing and Consumption Goods. Workers of education and family types $e k$ live in a neighborhood $n$. They spend their entire disposable income $Y_{n}^{e}$ on housing $H$ and the homogeneous consumption good $C$ by solving the following utility maximization problem:

$$
\max _{C, H}\left\{\log \left[\exp \left(\mathcal{A}_{n}^{e k}\right)\left(\frac{H}{\alpha^{e k}}\right)^{\alpha^{e k}}\left(\frac{C}{1-\alpha^{e k}}\right)^{1-\alpha^{e k}}\right]\right\},
$$

subject to the budget constraint:

$$
Y_{n}^{e}=\left(1-\tau_{g}^{w}\right)\left(1-\tau_{s}^{w}\right) w_{m}^{e}+D w_{m}^{e}=r_{n} H+C,
$$

where $\mathcal{A}_{n}^{e k}$ denotes amenities, $w_{m}^{e}$ wages, $r_{n}$ rents, and $\alpha^{e k}$ housing expenditure shares. $\tau_{g}^{w}$ and $\tau_{s}^{w}$ denote federal and state wage taxes. $D w_{m}^{e}$ is the reimbursement of aggregate rent payments.

The utility maximization yields the following indirect utility function:

$$
U_{n}^{e k}=\mathcal{A}_{n}^{e k}+\log \left(Y_{n}^{e}\right)-\alpha^{e k} \log \left(r_{n}\right) .
$$

Dynamic Decision Problem. The expected utility of young adults with education $e$, family type $k$ and childhood location $m$ before moving is given by:

$$
V_{t}(m, e, k)=\mathbb{E}_{\epsilon_{n^{\prime}} \max _{n^{\prime} \in \mathbb{N}}}\left\{U_{n^{\prime} t}^{e k}-\mathcal{C}_{m m^{\prime} t}^{e k}+\sigma_{N} \epsilon_{n^{\prime} t}+1_{k=1} \beta O_{t}\left(n^{\prime}, e\right)\right\},
$$

where expectations are taken over young adults' location taste shocks $\epsilon_{n^{\prime}} \cdot \mathcal{C}_{m m^{\prime}}^{e k}$ are moving costs, $\sigma_{N}$ is the dispersion of location taste shocks, and $\beta$ is the altruism parameter. $O(n, e)$ denotes the child opportunity value (i.e., the expected utility) of children who are born to parents of education $e$ and raised in childhood location $n$. Child opportunity values can be expressed as follows:

$$
O_{t}\left(n^{\prime}, e\right)=\mathbb{E}_{e_{e^{\prime}}} \max _{e^{\prime}}\left[1_{e^{\prime}=h} \mathcal{Q}_{n^{\prime} t}^{e}+\sigma_{E} \epsilon_{e^{\prime} t}+\sum_{k^{\prime}} \operatorname{Pr}_{t}\left(k^{\prime} \mid e^{\prime}\right) V_{t+1}\left(m^{\prime}, e^{\prime}, k^{\prime}\right)\right],
$$

where expectations are taken over children's education taste shocks $\epsilon_{e^{\prime}}$. $\mathcal{Q}_{n}^{e}$ denotes local education quality, $\sigma_{E}$ is the dispersion of education taste shocks, and $\operatorname{Pr}(k \mid e)$ are fertility probabilities. We define continuation values before knowing fertility as $R(m, e)=$ 
$\sum_{k} \operatorname{Pr}(k \mid e) V(m, e, k)$. We assume that location and education taste shocks are extreme value distributed. This assumption allows us to express value functions and child opportunity values in closed form as:

(OA.2) $V_{t}(m, e, k)=\sigma_{N} \log \left(\sum_{n^{\prime} \in \mathbb{N}} \exp \left[\frac{1}{\sigma_{N}} U_{n^{\prime} t}^{e k}-\frac{1}{\sigma_{N}} \mathcal{C}_{m m^{\prime} t}^{e k}+11_{k=1} \frac{\beta}{\sigma_{N}} O_{t}\left(n^{\prime}, e\right)\right]\right)$ and

$$
O_{t}(n, e)=\sigma_{E} \log \left(\sum_{e^{\prime}} \exp \left[\frac{1}{\sigma_{E}} 1_{e^{\prime}=h} \mathcal{Q}_{n t}^{e}+\frac{1}{\sigma_{E}} R_{t+1}\left(m, e^{\prime}\right)\right]\right)
$$

The share of young adults with education $e$ and family type $k$ that move from childhood location $m$ to adulthood location $n^{\prime}$ is given by:

$$
\operatorname{Pr}_{t}\left(n^{\prime} \mid m, e, k\right)=\frac{\exp \left[\frac{1}{\sigma_{N}} U_{n^{\prime} t}^{e k}-\frac{1}{\sigma_{N}} \mathcal{C}_{m m^{\prime} t}^{e k}+1_{k=1} \frac{\beta}{\sigma_{N}} O_{t}\left(n^{\prime}, e\right)\right]}{\sum_{n^{\prime \prime} \in \mathbb{N}} \exp \left[\frac{1}{\sigma_{N}} U_{n^{\prime \prime} t}^{e k}-\frac{1}{\sigma_{N}} \mathcal{C}_{m m^{\prime \prime} t}^{e k}+1_{k=1} \frac{\beta}{\sigma_{N}} O_{t}\left(n^{\prime \prime}, e\right)\right]},
$$

and the share of children in location $n$ with parents of education $e$ who choose education $e^{\prime}$ is:

$$
\operatorname{Pr}_{t}\left(e^{\prime} \mid n, e\right)=\frac{\exp \left[\frac{1}{\sigma_{E}} 1_{e^{\prime}=h} \mathcal{Q}_{n t}^{e}+\frac{1}{\sigma_{E}} R_{t+1}\left(m, e^{\prime}\right)\right]}{\sum_{e^{\prime \prime}} \exp \left[\frac{1}{\sigma_{E}} 1_{e^{\prime \prime}=h} \mathcal{Q}_{n t}^{e}+\frac{1}{\sigma_{E}} R_{t+1}\left(m, e^{\prime \prime}\right)\right]} .
$$

These analytical expressions are standard in the literature under the assumption of extreme value distributed shocks. A useful reference for the derivations is Redding and Rossi-Hansberg (2017).

\section{Law of Motion}

Individuals' residential and educational choices and their exogenous fertility probabilities determine how the distribution of workers evolves dynamically across locations, skill levels, and family types. The resulting law of motion is given by:

$$
L_{n^{\prime} t}^{e^{\prime} k^{\prime}}=\sum_{m \in \mathbb{M}} \operatorname{Pr}_{t}\left(n^{\prime} \mid m, e^{\prime}, k^{\prime}\right) \operatorname{Pr}_{t-1}\left(k^{\prime} \mid e^{\prime}\right) \sum_{e} \sum_{n \in \mathbb{N}_{m}} \operatorname{Pr}_{t-1}\left(e^{\prime} \mid n, e\right) \frac{L_{n t-1}^{e 1}}{\operatorname{Pr}_{t-1}(k \mid e)},
$$

where $L_{n t-1}^{e 1}$ denotes the number of parents with education $e$ who live in neighborhood $n$ at time $t-1$. 


\section{Market Clearing}

Rental market clearing in each neighborhood determines the local rental rate $r_{n}$ as a function of local fixed housing supply $\mathcal{H}_{n}$ and residents' local housing demand:

$$
\mathcal{H}_{n t}=\frac{1}{r_{n t}} \sum_{e} \sum_{k} \alpha^{e k} Y_{n t}^{e} L_{n t}^{e k} .
$$

Labor market clearing determines wages for each skill type $w_{m}^{e}$ which equalize firms' local labor demand and residents' local labor supply:

$$
w_{m t}^{e}=\mathcal{S}_{m t}^{e}\left(L_{m t}^{e}\right)^{\rho-1} \mathcal{Z}_{m t}\left[\mathcal{S}_{m t}^{h}\left(L_{m t}^{h}\right)^{\rho}+\mathcal{S}_{m t}^{l}\left(L_{m t}^{l}\right)^{\rho}\right]^{\frac{1}{\rho}-1} .
$$

\section{Recursive Equilibrium}

The recursive equilibrium is defined conditional on a list of exogenous parameters. Structural parameters are housing expenditure shares $\left(\alpha^{e k}\right)$, altruism $(\beta)$, dispersion of location and education taste shocks $\left(\sigma_{E}, \sigma_{N}\right)$, causal effects of school funding on the probability of attending college $\left(\gamma^{e}\right)$, the elasticity of substitution between low- and high-skill workers in production $(\rho)$, and probability of becoming a parent, conditional on education $(\operatorname{Pr}(k \mid e))$. We denote the collection of these parameters by $\gamma \equiv\left\{\alpha^{e k}, \beta, \sigma_{E}, \sigma_{N}, \gamma^{e}, \rho, \operatorname{Pr}(k \mid e)\right\}$. Other parameters are tax rates and school funding allocation rules from federal, state, and local governments, which we denote by: $\Gamma_{t} \equiv\left\{\tau_{g t}^{w}, \tau_{s t}^{w}, \tau_{n t}^{r}, \delta_{n t}^{g}, \delta_{n t}^{s}\right\}$. Last, time-varying regional characteristics include productivity, skill intensity, moving costs, amenities, housing supply, and the exogenous component of education quality, which we denote by: $\Theta_{t} \equiv\left\{\mathcal{Z}_{m t}, \mathcal{S}_{m t}^{e}, \mathcal{C}_{m m^{\prime} t}^{e k}, \mathcal{A}_{n t}^{e k}, \mathcal{H}_{n t}, \mathcal{K}_{n t}^{e}\right\}$.

Conditional on these exogenous parameters, the equilibrium definition is similar to that of our core framework presented in Section 3. Endogenous factor prices are now local wages and rents $\left\{w_{m t}^{e}, r_{n t}\right\}$.

\section{B. Data Construction and Summary Statistics}

The estimation of our model relies on the following key data moments: moving flows across commuting zones (CZs), wages by education level and $\mathrm{CZ}$, and the county level population stocks, education choices for children from low- and high-skill families, per student school funding and rents. We now describe the sources and construction of our data sets. Table OA.3 provides summary statistics. 


\section{B.1 Data Construction}

Moving Flows by Education and Family Type across Commuting Zones. We construct moving flows across CZs for each education and family type using individual-level data from the decennial census in 1990 and 2000 and the American Community Survey (ACS) in 2006-2010. We obtain the data from the Integrated Public Use Microdata Series (IPUMS) (see Ruggles et al. (2017)). In our model, we assume that individuals move only once in their life, after finishing their education and before joining the labor market. To capture such moves in the data, we restrict the sample to young adults who are between ages 35 and 50 years. The data provide information on respondents' current and past Public Use Microdata Area (PUMA) of residence. The 1990 and 2000 census reports PUMAs of residence 5 years ago, the 2006-2010 ACS 1 year ago, which allow us to construct 5-year moving flows for 1990 and 2000 and 1-year moving flows for 2010. We then adjust the 1-year moving flows by simulating them forward to construct a consistent panel of 5-year moving flows across all three decades (more detail below). We use a crosswalk to map PUMAs to CZs.

Adjusting 1-year Moving Flows. To construct consistent 5-year moving flows across all three decades, we make the following adjustment to the 1-year moving flows that we observe in the 2006-2010 data. We start with the accounting identity:

$$
L_{m^{\prime}, t}=\mathbf{B}_{m m^{\prime}, t, t-1} L_{m, t-1},
$$

where $L_{m, t-1}$ is the population in origin $m$ before moving and $L_{m, t}$ is the population in destination $m$ after moving. $\mathbf{B}_{m m^{\prime}, t, t-1}$ denotes the 1-year moving matrix, i.e., the population share that moves from origin $m$ to destination $m^{\prime}$ between years $t-1$ and $t$. These objects are observed in the data. We simulate the 1-year moving matrix forward five times to construct 5-year moving flows as:

$$
L_{m^{\prime}, t}=\mathbf{B}_{m m^{\prime}, t, t-5} L_{m, t-5} \approx\left(\mathbf{B}_{m m^{\prime}, t, t-1}\right)^{5} L_{m, t-5} .
$$

We use this procedure separately for each education and family type.

Robustness of the Moving Flow Adjustment. In our model estimation, we use moving flows to identify bilateral moving costs across CZs and the utility levels offered by each $\mathrm{CZ}$. To verify how the adjustment procedure affects these results, we exploit the fact that we observe 1-year and 5-year moving flows for 2000 because the ACS and the decennial census overlap in this year. For 2000, we can therefore compare estimates of moving costs and utilities that we obtain from observed 1-year moving flows (ACS), observed 5-year moving flows (census), and simulated 5-year moving flows. We estimate moving costs 
and utility levels by PPML from Equation (16) separately for each of the three sets of moving flows. Due to a small sample size, we use moving flows across states (excluding Alaska, Hawaii and DC) and we pool all family and education types who are older than 25 years. Table OA.1 shows that the level and dispersion of estimated moving costs are very similar when using the observed or simulated 5-year moving flows. CZ utility levels are identified from destination fixed effects up to a constant of normalization. The variation of utility across CZs is therefore the statistic of interest, which is similar for estimates from observed and simulated 5-year moving flows (cf. Table OA.1). These findings suggest that the adjustment of 1-year moving flows does a good job at replicating the patterns of observed 5-year moving flows.

TABle OA.1: Moving Cost And CZ-Utility
with Simulated And ObServed Moving Flows

\begin{tabular}{|c|c|c|}
\hline Data Sample & Mean & Std. Dev. \\
\hline \multicolumn{3}{|c|}{ Panel A: Moving Cost } \\
\hline 1-yr observed flows & 7.16 & 1.33 \\
\hline 5-yr simulated flows & 5.55 & 1.06 \\
\hline 5-yr observed flows & 5.82 & 1.09 \\
\hline \multicolumn{3}{|c|}{ Panel B: CZ-Utility (Fixed Effects) } \\
\hline 1-yr observed flows & 0.20 & 0.32 \\
\hline 5-yr simulated flows & 0.21 & 0.33 \\
\hline 5-yr observed flows & 0.14 & 0.33 \\
\hline \multicolumn{3}{|c|}{$\begin{array}{l}\text { Notes: This table presents estimates of moving } \\
\text { cost and CZ-utility obtained from estimating Equa- } \\
\text { tion } 16 \text { by Poisson pseudo-maximum likelihood } \\
\text { (PPML). The estimation is done separately with } \\
2000 \text { data from observed 1-year moving flows } \\
\text { (ACS), observed 5-year moving flows (census), and } \\
\text { simulated 5-year moving flows. The sample in- } \\
\text { cludes bilateral moving flows across } 33 \text { states, so } \\
N=33^{2}=1,089 \text {. Estimates of moving costs and } \\
\text { the dispersion of CZ-utilities are similar when us- } \\
\text { ing observed or simulated 5-year moving flows. }\end{array}$} \\
\hline
\end{tabular}

Population Stocks by Education and Family Type in Each County. We obtain data on local population stocks by education and family type from the Education Demographic and Geographic Estimates (EDGE). The data are special tabulations of census data and 
are provided by the National Center for Education Statistics (NCES). ${ }^{20}$ For 1990, 2000, and 2010, we obtain information on the number of households by education level and by "presence of children" for each school district. In 2010, the data are further disaggregated into age groups. We aggregate population stocks to the county level, which provides our empirical measure of population by education and family type in each county.

Wages by Education Level for Each Commuting Zone. We use data on annual labor income from the 5 percent microdata samples from the 1990 and 2000 decennial census and the 2006-2010 ACS from IPUMS. We restrict the sample to full-time workers between 35 and 50 years where we define full-time work to be at least 48 weeks per year and on average between 36 and 60 hours per week. We use the individual-level data to estimate Mincer regressions. We control for a range of worker characteristics to isolate the variation of wage income that is due to locations and education levels. We estimate the following regression across individuals $i$ in the data:

$$
\log \left(w_{i}\right)=D_{i, f \text { emale }}+D_{i, \text { black }}+\alpha_{1} \exp _{i}+\alpha_{2} \exp _{i}^{2}+\alpha_{3} \exp _{i}^{3}+\alpha_{4} \exp _{i}^{4}+D_{e} D_{m}+\epsilon_{i}
$$

where $w_{i}$ is annual gross wage income, $D_{\text {female }}$ is a dummy that indicates if the worker is female, $D_{\text {black }}$ indicates if the worker is black, and $\exp _{i}$ are years of experience. The regression specification includes the full set of interactions between location and education fixed effects $D_{e} D_{m}$. These fixed effects estimate wages by education level and location up to a constant of normalization. We use a crosswalk to map PUMAs to CZs, applying population weights if borders overlap.

Education Outcomes by County. We obtain data on education outcomes by childhood county from Chetty and Hendren (2018b). For each childhood county in the US, the authors provide children's college attendance rates and the causal effects of the county on children's college attendance rates for families at the 25th and 75th percentiles of the national income distribution. Causal effects are estimated with quasi-experimental evidence from movers. We map our model to the causal effect estimates because our model predicts that all differences in local education outcomes are causal to the childhood county (conditional on parental education). ${ }^{21}$ We use families' income percentile as proxies for low and high education levels. Causal effects are estimated relative to the average county, so that their level is not identified. We therefore adjust the levels to match the aggregate

\footnotetext{
${ }^{20}$ The data are available at https://nces.ed.gov/programs/edge/.

${ }^{21}$ In our model, children's education choices depend on parental education, childhood location and idiosyncratic education taste shocks. Education taste shocks are i.i.d. distributed and realized only after families chose their adulthood neighborhood. Families therefore can not sort into neighborhoods based on the realization of education taste shocks, so that average taste shocks do not differ across neighborhoods. Future research could extend our model to study the effects of this type of sorting.
} 
college enrollment rate respectively for children from low- and high-income families.

School Funding by County. We obtain school funding data at the school-district level from the NCES. The annual Finance Survey (F-33) provides information on school districts' funding from federal, state, and local sources. In addition, we obtain information on the number of students in each school district from the Common Core of Data (CCD) files. We aggregate the data to the county level.

Rental Rates by County. We estimate county rental rates from tabulations of US census data provided by the National Historical Geographic Information System (NHGIS). The NHGIS provides information on median rent and several housing characteristics at the block-group level. Block groups are small geographic units. Each county nests multiple block groups. We use these data to estimate hedonic price regressions, following Eeckhout et al. (2014). We control for a range of each block group's housing characteristics to isolate the variation in rents across counties. We regress block group $j$ 's median rent on housing characteristics and county fixed effects so that:

$$
\log \left(\text { rent }_{j}\right)=\log \left(\text { year }_{j}\right)+\text { rooms }_{j}+\text { unit }_{j}+T_{n}+\epsilon_{j},
$$

where $j$ indexes each block group, $r_{j}$ is median gross rent in each block group, year ${ }_{j}$ is the median year of construction, rooms $j$ is the median number of rooms, and $u n i t_{j}$ is a dummy that indicates the most common type of structure in each block group. $T_{n}$ are county fixed effects. These fixed effects identify counties' rental rates per quality-adjusted housing unit up to a constant of normalization. We estimate the hedonic price regressions separately for each decade and weigh block groups by their number of renters. Table OA.2 shows the regression results.

Bartik Labor Demand Shocks by Commuting Zone. We compute Bartik-like local labor demand shocks using US census data from 1980, 1990, 2000, and ACS data from 20062010 provided by IPUMS. To compute changes in industries' national wages for each skill type, we restrict the sample to full-time workers between 35 and 50 years and we drop observations with weekly wages below 150 USD. We define industries by the 2-digit SIC codes provided in the census data. To avoid endogeneity issues, we compute national changes in industry wages for each $\mathrm{CZ}$ by excluding the respective $\mathrm{CZ}$ from the data. We then weigh each industry's national wage changes by CZs' industry-level employment in 1980. We implement the procedure separately for low- and high-skill workers. The census data provide PUMA identifiers that we map to CZs with a crosswalk.

Variables to Parameterize Moving Costs across Commuting Zones. We obtain CZ characteristics from the 1990 and 2000 US census and the 2006-2010 ACS. For each CZ, we 
TAble OA.2: Hedonic PRICE Regressions fOR Rented Housing

\begin{tabular}{|c|c|c|c|}
\hline & \multicolumn{3}{|c|}{ Log Median Gross Rent } \\
\hline & 1990 & 2000 & 2010 \\
\hline 2 Rooms & $\begin{array}{c}0.190^{* * *} \\
(0.012)\end{array}$ & $\begin{array}{c}0.382^{* * *} \\
(0.013)\end{array}$ & $\begin{array}{c}0.371^{* * *} \\
(0.023)\end{array}$ \\
\hline 3 Rooms & $\begin{array}{c}0.278^{* * *} \\
(0.011)\end{array}$ & $\begin{array}{c}0.487^{* * *} \\
(0.012)\end{array}$ & $\begin{array}{c}0.504^{* * *} \\
(0.022)\end{array}$ \\
\hline 4 Rooms & $\begin{array}{c}0.356^{* * *} \\
(0.011)\end{array}$ & $\begin{array}{c}0.545^{* * *} \\
(0.012)\end{array}$ & $\begin{array}{c}0.534^{* * *} \\
(0.022)\end{array}$ \\
\hline 5 Rooms & $\begin{array}{c}0.468^{* * *} \\
(0.011)\end{array}$ & $\begin{array}{c}0.641^{* * *} \\
(0.012)\end{array}$ & $\begin{array}{c}0.602^{* * *} \\
(0.022)\end{array}$ \\
\hline 6 Rooms & $\begin{array}{c}0.578^{* * *} \\
(0.011)\end{array}$ & $\begin{array}{c}0.738^{* * *} \\
(0.012)\end{array}$ & $\begin{array}{c}0.694^{* * *} \\
(0.022)\end{array}$ \\
\hline 7 Rooms & $\begin{array}{c}0.664^{* * *} \\
(0.012)\end{array}$ & $\begin{array}{c}0.821^{* * *} \\
(0.013)\end{array}$ & $\begin{array}{c}0.763^{* * *} \\
(0.022)\end{array}$ \\
\hline 8 Rooms & $\begin{array}{c}0.756^{* * *} \\
(0.014)\end{array}$ & $\begin{array}{c}0.908^{* * *} \\
(0.014)\end{array}$ & $\begin{array}{c}0.833^{* * *} \\
(0.023)\end{array}$ \\
\hline 9+ Rooms & $\begin{array}{c}0.815^{* * *} \\
(0.024)\end{array}$ & $\begin{array}{c}1.029^{* * *} \\
(0.021)\end{array}$ & $\begin{array}{c}0.895^{* * *} \\
(0.026)\end{array}$ \\
\hline 1-family house, attached & $\begin{array}{c}-0.038^{* * *} \\
(0.003)\end{array}$ & $\begin{array}{c}-0.024^{* * *} \\
(0.004)\end{array}$ & $\begin{array}{c}-0.032^{* * *} \\
(0.004)\end{array}$ \\
\hline 2-family building & $\begin{array}{c}-0.009^{* * *} \\
(0.003)\end{array}$ & $\begin{array}{c}-0.004 \\
(0.003)\end{array}$ & $\begin{array}{c}-0.056^{* * *} \\
(0.003)\end{array}$ \\
\hline 3-family building & $\begin{array}{c}-0.020^{* * *} \\
(0.002)\end{array}$ & $\begin{array}{c}-0.029^{* * *} \\
(0.002)\end{array}$ & $\begin{array}{c}-0.088^{* * *} \\
(0.003)\end{array}$ \\
\hline 5-family building & $\begin{array}{c}-0.047^{* * *} \\
(0.002)\end{array}$ & $\begin{array}{c}-0.043^{* * *} \\
(0.002)\end{array}$ & $\begin{array}{c}-0.114^{* * *} \\
(0.002)\end{array}$ \\
\hline 10-family building & $\begin{array}{c}-0.016^{* * *} \\
(0.002)\end{array}$ & $\begin{array}{c}-0.014^{* * *} \\
(0.003)\end{array}$ & $\begin{array}{c}-0.102^{* * *} \\
(0.002)\end{array}$ \\
\hline 20-family building & $\begin{array}{c}-0.037^{* * *} \\
(0.002)\end{array}$ & $\begin{array}{c}-0.046^{* * *} \\
(0.003)\end{array}$ & $\begin{array}{c}-0.129 * * * \\
(0.003)\end{array}$ \\
\hline 50-family building & $\begin{array}{c}-0.079^{* * *} \\
(0.002)\end{array}$ & $\begin{array}{c}-0.056^{* * *} \\
(0.002)\end{array}$ & $\begin{array}{c}-0.150^{* * *} \\
(0.003)\end{array}$ \\
\hline Log Median Construction Year & $\begin{array}{c}10.483^{* * *} \\
(0.102)\end{array}$ & $\begin{array}{c}10.649 * * * \\
(0.100)\end{array}$ & $\begin{array}{c}9.168^{* * *} \\
(0.093)\end{array}$ \\
\hline Observations & 211,977 & 201,714 & 186,250 \\
\hline R-Squared & 0.565 & 0.527 & 0.529 \\
\hline
\end{tabular}

Notes: Standard errors in parentheses, ${ }^{* * *} \mathrm{p}<0.01,{ }^{* *} \mathrm{p}<0.05,{ }^{*} \mathrm{p}<0.1$. This table presents the results of hedonic price regressions that regress log rents on several proxies for housing quality and county fixed effects. Regressions are estimated at the block-group level and separately for each decade. To proxy housing quality in each block group, we use data on the median construction year, the median number of rooms and the mode of housing unit types. Number of rooms and housing type enter as categorical variables with the omitted categories being "1 Room" and "Detached one-family home."

$$
\text { OA - } 8
$$


observe the state(s) and division to which it belongs. CZs can overlap state borders, so we allow CZs to belong to up to three different states. CZs are classified as coastal if they are part of census division 1 or 9 and as urban if they are part of a metropolitan statistical area (MSA). Distances between the centroids of two CZs are calculated in ArcGIS using shapefiles from the census TIGER files.

\section{B.2 Summary Statistics}

We provide population-weighted summary statistics of the key data moments in Table OA.3 using data from 2006-2010.

Panel A shows wage rates for each skill level. We normalize total US wages to have a population-weighted mean of one. Low-skill wages average 0.7 with a standard deviation of 0.07 . High-skill wages average 1.3 with a standard deviation of 0.2 . The average skill premium-defined as the log ratio between low- and high-skill wages-is 57 percent with a standard deviation of 8 percent.

Panel B shows county-level rental rates normalized to have a population-weighted mean of one. The standard deviation of county rent is 0.3 . Rent in the county at the 90th percentile is 47 percent above average. In the county at the 10th percentile, rent is only 64 percent of the average.

Annual per student school funding is on average $\$ 12,430$ (Panel C) which varies from $\$ 9,254$ in the county at the 10 th percentile to $\$ 17,608$ in the county at the 90 th percentile. Counties receive on average 12 percent of their school funding from the federal government, which has a standard deviation of 5 percent. State and local governments each provide on average 44 percent of funds with a standard deviation of 13.5 percent for state funding and 15.5 percent for local funding.

Panel D documents children's college attendance rates and the causal effects of childhood counties on children's college attendance rates for families at the 25th and 75th percentile of the national income distribution. We obtain these estimates from Chetty and Hendren (2018b). Children's average college attendance rate is 55.8 percent for low-income families and 84.2 percent for high-income families with standard deviations of 9 percent for low-income families and 4 percent for high-income families. Chetty and Hendren (2018b) estimate causal effects of childhood counties on college attendance rates per year of exposure and find linear exposure effects for ages below 20 years. We therefore multiply the authors' annual estimates by 20 to measure the total causal effect of spending an entire childhood in a given county. The causal effects are estimated relative to the average, so that their level is not identified. Causal effects vary substantially across counties with a 
standard deviation of 15 percentage points (p.p.) for children from low- and high-income families. Children from low-income families who spend their entire childhood in a county at the 10th (90th) percentile have a 14 p.p. lower (higher) probability of attending college than the average child from the same income group. For children from high-income families, the probability is 8 p.p. lower (higher) in the county at the 10th (90th) percentile.

TAble OA.3: Summary Statistics of Regional Data

\begin{tabular}{|c|c|c|c|c|c|}
\hline & Obs. & Mean & Std. Dev. & p10 & p90 \\
\hline \multicolumn{6}{|c|}{ Panel A: Wages and Skill Premia across CZs } \\
\hline Wages for Low-Skill Workers & 692 & 0.69 & 0.07 & 0.6 & 0.8 \\
\hline Wages for High-Skill Wor & 692 & 1.27 & 0.19 & 1.01 & 1.49 \\
\hline Skill Premia (\%) & 692 & 57 & 7.9 & 47.4 & 67.3 \\
\hline \multicolumn{6}{|c|}{ Panel B: Housing Rents across Counties } \\
\hline Rental Rates & 2,841 & 1 & 0.31 & 0.64 & 1.47 \\
\hline \multicolumn{6}{|c|}{ Panel C: School Funding across Counties } \\
\hline School Funding per Student (\$) & 2,841 & 12,430 & 3,704 & 9,254 & 17,608 \\
\hline \multicolumn{6}{|l|}{ Share of Local Funding from (\%) } \\
\hline Federal Government & 2,841 & 11.8 & 5.0 & 5.4 & 17.8 \\
\hline State Government & 2,841 & 43.8 & 13.5 & 25.8 & 61.6 \\
\hline Local Government & 2,841 & 44.4 & 15.5 & 23.8 & 65.9 \\
\hline \multicolumn{6}{|c|}{ Panel D: College Attendance Rates and Causal Effects across Counties } \\
\hline \multicolumn{6}{|c|}{ College Attendance Rates by County (\%) } \\
\hline Low-Income Parents & 2,840 & 55.8 & 9.1 & 44.7 & 68.4 \\
\hline High-Income Parents & 2,840 & 84.2 & 4.2 & 79.0 & 88.8 \\
\hline \multicolumn{6}{|c|}{ Causal Effect of County on College Attendance Rate (p.p.) } \\
\hline Low-Income Parents & 2,350 & - & 14.8 & -13.7 & 14.0 \\
\hline High-Income Parents & 2,350 & - & 15.3 & -8.2 & 7.8 \\
\hline
\end{tabular}

Notes: All summary statistics are population-weighted. Aggregate wages and rents are normalized to have a population-weighted mean of 1 . 


\section{Estimation Details}

\section{C.1 Calibrated Parameters}

Housing Expenditure Shares. Housing expenditure shares $\alpha^{e k}$ are calibrated to expenditure data from the 2011 Consumer Expenditure Survey (CEX) provided by the Bureau of Labor Statistics (BLS). The CEX file fmli111x provides information on individuals' education, presence of children in the household, expenditure on housing (variable sheltcq) and total expenditure (variable totexpcq). We restrict our sample to families with and without children (fam_types 1-4) who earn a minimum weekly income of 150 USD. We use these data to compute average housing expenditure shares for each education and family type in our model. The average low-skill (high-skill) family with children spends 38 (36) percent of its income on housing compared to 34 (33) percent for those without children.

Fertility Probability. We set fertility probabilities for each education group, $\operatorname{Pr}(k \mid e)$, to the observed fraction of workers with education $e$ where children are present in the household. We obtain this fraction from US census data from IPUMS. We restrict the sample to ages between 35 to 44 years. Low-skill workers have a fertility probability of 56 percent, whereas high-skill workers have a fertility probability of 63 percent.

Elasticity of Substitution between Worker Types in Production. We follow Ciccone and Peri (2005) and set the elasticity of substitution across low- and high-skill workers to 1.5, which implies that $\rho=1 / 3$. Ciccone and Peri (2005) use changes in compulsory schooling laws in US cities to isolate exogenous variation in skill supply at the city level. They use microdata from the US census and define workers to be high-skill if they have education beyond a high school diploma, as we do in our paper. Other studies find similar results such as Katz and Murphy (1992) (1.41) and Heckman et al. (1998) (1.44). Autor et al. (1998) review the literature.

Tax Rates and Rent Reimbursement. Federal and state governments tax wages and local governments tax rents. We denote the tax rates respectively by $\tau_{g}^{w}, \tau_{s}^{w}, \tau_{n}^{r}$, where $g$ denotes the federal government and $s$ denotes state governments. We assume that all tax revenues are used for school funding and that each level of government balances its budget. Each state funds schools only within its borders. These assumptions allow us to identify tax rates from the budget constraints. For states, budget constraints are equal to:

(OA.10)

$$
\sum_{n \in \mathbb{N}_{s}} F_{n}^{s}=\tau_{s}^{w} \sum_{n \in \mathbb{N}_{s}} \sum_{e} w_{m}^{e} L_{n}^{e}
$$


where $F_{n}^{s}$ is total school funding from state $s$ to neighborhood $n$. Aggregating over neighborhoods in each state $\left(n \in \mathbb{N}_{s}\right)$ derives states' total school expenditure. The federal budget constraint is equal to:

$$
\sum_{n \in \mathbb{N}} F_{n}^{g}=\tau_{g}^{w} \sum_{n \in \mathbb{N}} \sum_{e}\left(1-\tau_{s}^{w}\right) w_{m}^{e} L_{n}^{e}
$$

where we allow for deductibility of state taxes. $F_{n}^{g}$ is total federal school funding given to neighborhood $n$. We can identify federal and state wage taxes using these budget constraints and local data on wages, workers by skill type, and school funding from federal and state governments to each neighborhood.

Local governments tax rents at a rate $\tau_{n}^{r}$. Tenants pay a rental rate $r_{n}=\left(1+\tau_{n}^{r}\right) r_{n}^{*}$, which consists of market rate $r_{n}^{*}$ and tax rate $\tau_{n}^{r}$. For local governments, budget constraints are equal to:

$$
F_{n}^{n}=\tau_{n}^{r} r_{n}^{*} H_{n}=\frac{\tau_{n}^{r}}{1+\tau_{n}^{r}} r_{n} \mathcal{H}_{n},
$$

where $F_{n}^{n}$ is total local school funding (raised and spent) in neighborhood $n$. Total rental expenditure in each neighborhood $n$ is given by:

$$
r_{n} \mathcal{H}_{n}=\sum_{e} \sum_{k} \alpha^{e k} Y_{n}^{e} L_{n}^{e k}
$$

which we can construct from calibrated housing expenditure shares $\hat{\alpha}^{e k}$, data on local population stocks $L_{n}^{e k}$ and information on local disposable income $Y_{n}^{e}$. Disposable income is equal to:

$$
Y_{n}^{e}=\left(1-\tau_{g}^{w}\right)\left(1-\tau_{s}^{w}\right) w_{m}^{e}+D w_{m}^{e}
$$

which we can construct from calibrated federal and state income tax rates and data on local wages. The "dividend" $D$ reimburses national rental income back to all workers in proportion to their wage income. $D$ is therefore equal to the ratio between national rent income (after taxes) and national wage income:

$$
D=\frac{\sum_{n \in \mathbb{N}} r_{n}^{*} \mathcal{H}_{n}}{\sum_{m \in \mathbb{M} e} \sum_{m} w_{m}^{e} L_{m}^{e}}=\frac{\sum_{n \in \mathbb{N}} r_{n} \mathcal{H}_{n}-\sum_{n \in \mathbb{N}} F_{n}^{n}}{\sum_{m \in \mathbb{M} e} \sum_{m} w_{m}^{e} L_{m}^{e}} .
$$

Substituting Equation OA.13 into OA.14 and rearranging allows us to solve for $D$ as a function of observables in the following way:

$$
D=\frac{\sum_{n \in \mathbb{N}} \sum_{e} \sum_{k} L_{n}^{e k} \alpha^{e k} w_{m}^{e}\left(1-\tau_{g}^{w}\right)\left(1-\tau_{s}^{w}\right)-\sum_{n \in \mathbb{N}} F_{n}^{n}}{\sum_{n \in \mathbb{N} e} \sum_{k} L_{n}^{e k}\left(1-\alpha^{e k}\right) w_{m}^{e}} .
$$

With the calibrated value of $\hat{D}$ at hand, we can construct disposable local income $\hat{Y}_{n}^{e}$ and 
total rental expenditure $r_{n} H_{n}$ in each neighborhood (Equation OA.13). Using these measures, we can then solve for the local tax rate on rents $\tau_{n}^{r}$ (Equation OA.12).

Adjustment of School Funding Revenues. Our model aims at replicating the observed distribution of per student school funding across neighborhoods. In our model, the number of children in each neighborhood depends on the local share of parents. Parents have $1 / \operatorname{Pr}(k \mid e)$ children to keep total population constant, so the total number of children per neighborhood is given by: $\sum_{e} L_{n}^{e 1} / \operatorname{Pr}(k \mid e)$. In the data, locations vary in the average number of children per family. The model therefore does not precisely replicate the observed distribution of children across neighborhoods. To ensure that our model nevertheless matches the observed distribution of per student school funding, we adjust funding levels to account for differences in the total number of students. We use the adjusted school funding data to calibrate tax rates.

\section{C.2 Deriving an Expression for County-Utility}

In this section, we derive Equation 17, which expresses county-utility $x_{n}^{e k}$ as a function of county population stocks $L_{n}^{e k}$ and average CZ-utility $u_{m}^{e k}$ in the following way:

$$
\exp \left(x_{n}^{e k}\right)=\frac{L_{n}^{e k}}{L_{m}^{e k}} \exp \left(u_{m}^{e k}\right) \text {. }
$$

To derive this expression, we start from our model's prediction of moving flows of young adults from their childhood labor market $m$ to a destination labor market $m^{\prime}$, which is equal to:

$$
L_{m^{\prime}}^{e k}=\sum_{m \in \mathbb{M}} \sum_{n^{\prime} \in \mathbb{N}_{m^{\prime}}} \operatorname{Pr}\left(n^{\prime} \mid m, e, k\right) \tilde{L}_{m}^{e k}=\sum_{m \in \mathbb{M}} \frac{\exp \left(u_{m^{\prime}}^{e k}-c_{m m^{\prime}}^{e k}\right)}{\sum_{m^{\prime \prime} \in \mathbb{M}} \exp \left(u_{m^{\prime \prime}}^{e k}-c_{m m^{\prime \prime}}^{e k}\right)} \tilde{L}_{m}^{e k},
$$

where $\tilde{L}_{m}^{e k}$ are young adults with education $e$ and family type $k$ in their childhood location $m$. This equation follows from individuals' utility-maximizing moving choices (Equation OA.4). Rearranging this equation gives:

$$
\exp \left(u_{m^{\prime}}^{e k}\right)=L_{m^{\prime}}^{e k} /\left[\sum_{m \in \mathbb{M}} \frac{\exp \left(-c_{m m^{\prime}}^{e k}+\log \left(\tilde{L}_{m}^{e k}\right)\right)}{\sum_{m^{\prime \prime} \in \mathbb{M}} \exp \left(u_{m^{\prime \prime}}^{e k}-c_{m m^{\prime \prime}}^{e k}\right)}\right] .
$$

In addition, we can express the population stock in a county $n^{\prime}$ by summing moving inflows across origins, so that:

$$
L_{n^{\prime}}^{e k}=\sum_{m \in \mathbb{M}} \operatorname{Pr}\left(n^{\prime} \mid m, e, k\right) \tilde{L}_{m}^{e k}=\sum_{m \in \mathbb{M}} \frac{\exp \left(x_{n^{\prime}}^{e k}-c_{m m^{\prime}}^{e k}\right)}{\sum_{n^{\prime \prime} \in \mathbb{N}} \exp \left(x_{n^{\prime \prime}}^{e k}-c_{m m^{\prime \prime}}^{e k}\right)} \tilde{L}_{m}^{e k} .
$$


Pulling destinations' county-utilities $x_{n^{\prime}}^{e k}$ out of the sum, dividing and multiplying by $L_{m^{\prime}}^{e k}$ and rearranging the equation gives the desired expression that links county utility to county population stocks and CZ-utilities as follows:

$$
\begin{aligned}
\exp \left(x_{n^{\prime}}^{e k}\right) & =\frac{L_{n^{\prime}}^{e k}}{L_{m^{\prime}}^{e k}} L_{m^{\prime}}^{e k}\left[\sum_{m \in \mathbb{M}} \frac{\exp \left(-c_{m m^{\prime}}^{e k}+\log \left(\tilde{L}_{m}^{e k}\right)\right)}{\sum_{n^{\prime \prime} \in \mathbb{N}} \exp \left(x_{n^{\prime \prime}}^{e k}-c_{m m^{\prime \prime}}^{e k}\right)}\right] \\
& =\frac{L_{n^{\prime}}^{e k}}{L_{m^{\prime}}^{e k}} \exp \left(u_{m^{\prime}}^{e k}\right),
\end{aligned}
$$

where we used Equation OA.15 in the last row.

\section{C.3 Deriving an Expression for Child Opportunity Values}

We show that child opportunity values, $O_{t}(n, e)$, for children with parents of education $e$ in neighborhood $n$ can be expressed as:

$$
O_{t}(n, e)=R_{t+1}(m, l)-\sigma_{E} \log \left(\operatorname{Pr}_{t}(l \mid n, e)\right),
$$

where $\operatorname{Pr}_{t}(l \mid n, e)$ is the share of these children that remains low-skill and $R_{t+1}(m, l)$ is the continuation value of low-skill young adults before knowing their fertility shocks. We suppress time subscripts in the rest of the derivation. We start from the standard expressions for child opportunity values and education choices which follow from the assumption that education taste shocks are Gumbel distribution and which are equal to:

$$
O(n, e)=\sigma_{E} \log \left(\sum_{e^{\prime}} \exp \left[\frac{1}{\sigma_{E}} R\left(m, e^{\prime}\right)+\frac{1}{\sigma_{E}} 1_{e^{\prime}=h} \mathcal{Q}_{n}^{e}\right]\right),
$$

and

$$
\operatorname{Pr}\left(e^{\prime} \mid n, e\right)=\frac{\exp \left[\frac{1}{\sigma_{E}} R\left(m, e^{\prime}\right)+\frac{1}{\sigma_{E}} 1_{e^{\prime}=h} \mathcal{Q}_{n}^{e}\right]}{\sum_{e^{\prime \prime}} \exp \left[\frac{1}{\sigma_{E}} R\left(m, e^{\prime \prime}\right)+\frac{1}{\sigma_{E}} 1_{e^{\prime \prime}=h} \mathcal{Q}_{n}^{e}\right]}=\frac{\exp \left[\frac{1}{\sigma_{E}} R\left(m, e^{\prime}\right)+\frac{1}{\sigma_{E}} 1_{e^{\prime}=h} \mathcal{Q}_{n}^{e}\right]}{\exp \left[\frac{1}{\sigma_{E}} O(n, e)\right]},
$$

where we substitute Equation OA.16 into the denominator of the education choice equation. We evaluate education choices for the option of remaining low-skill at $e^{\prime}=l$ which gives:

$$
\operatorname{Pr}(l \mid n, e)=\frac{\exp \left[\frac{1}{\sigma_{E}} R(m, l)\right]}{\exp \left[\frac{1}{\sigma_{E}} O(n, e)\right]}
$$

Rearranging this equation gives the desired expression for child opportunity values. The derivation uses the fact that education is a binary choice. Education quality therefore shifts the probability of becoming high-skill relative to remaining low-skill which is equivalent to normalizing the (utility) cost of remaining low-skill to zero. 


\section{C.4 Estimation of Regional Characteristics}

\section{C.4.1 Inferring Regional Characteristics as Structural Residuals}

Production Technology. We use firms' first-order conditions (Equation OA.8) to identify the productivity parameters of the CES production function in each location. Firms' firstorder conditions imply that:

$$
\frac{\mathcal{S}_{m}^{h}}{\mathcal{S}_{m}^{l}}=\frac{w_{m}^{h}}{w_{m}^{l}}\left(\frac{L_{m}^{l}}{L_{m}^{h}}\right)^{\rho-1},
$$

where we can infer skill intensities $\mathcal{S}_{m}^{e}$ using the calibrated value of $\rho=1 / 3$, data on local wages and local labor stocks, and the property that $S_{m}^{h}+S_{m}^{l}=1$. We then use these results together with firms' first-order conditions to infer local total factor productivity $\mathcal{Z}_{m}$ as follows:

$$
\mathcal{Z}_{m}=\frac{w_{m}^{e}}{\mathcal{S}_{m}^{e}\left(L_{m}^{e}\right)^{\rho-1} \times\left(\mathcal{S}_{m}^{l}\left(L_{m}^{l}\right)^{\rho}+\mathcal{S}_{m}^{h}\left(L_{m}^{h}\right)^{\rho}\right)^{\frac{1-\rho}{\rho}}} .
$$

Housing Supply. We infer housing supply $\mathcal{H}_{n}$ to ensure that local rental markets clear in each neighborhood. To do so, we use Equation OA.7 and local data on rent expenditure and rental rates.

Exogenous Education Quality. We infer the exogenous component of local education quality from data on local education probabilities, local school funding, and our estimates of local returns to education $R(m, e)$ in the following way:

$$
\mathcal{K}_{n}^{e}=R(m, h)-R(m, l)+\gamma^{e} \log \left(f_{n}\right)-\sigma_{E} \log \left(\frac{\operatorname{Pr}(h \mid n, e)}{1-\operatorname{Pr}(h \mid n, e)}\right) .
$$

Amenities. We infer amenities for each education type from estimated county-utilities of non-parents and from data on real disposable income in the following way:

$$
a_{n}^{e}=x_{n}^{e 0}-\frac{1}{\sigma_{N}} I_{n}^{e 0}
$$

\section{C.4.2 Identifying the Level of Amenities and Education Quality}

Amenities for each education type are identified from residential choices of non-parents which are static decisions. A change in amenity levels affects non-parents' utility only through an additive shifter of flow utilities. Such an additive increase or decrease in utility in all locations does not affect residential choices because the shifter simply cancels from the numerator and denominator of residential choice probabilities. Amenities are 
therefore identified only up to constant of normalization. In this section, we show that we can normalize amenities for each skill type without loss of generality because the dynamic residential choices of parents as well as children's dynamic education choices are also invariant to amenity levels.

First, we show that a normalization of amenity levels does not affect parents' residential choices conditional on children's education choices. To do so, we write parents' residential choices as:

(OA.18)

$$
\operatorname{Pr}\left(n^{\prime} \mid m, e, 1\right)=\frac{\exp \left[a_{n^{\prime}}^{e}+\frac{1}{\sigma_{N}} I_{n^{\prime}}^{e 1}-c_{m m^{\prime}}^{e 1}+\frac{\beta}{\sigma_{N}} R\left(m^{\prime}, l\right)-\frac{\beta \sigma_{E}}{\sigma_{N}} \log \left(\operatorname{Pr}\left(l \mid n^{\prime}, e\right)\right)\right]}{\sum_{n^{\prime \prime} \in \mathbb{N}} \exp \left[a_{n^{\prime \prime}}^{e}+\frac{1}{\sigma_{N}} I_{n^{\prime \prime}}^{e 1}-c_{m m^{\prime \prime}}^{e 1}+\frac{\beta}{\sigma_{N}} R\left(m^{\prime \prime}, l\right)-\frac{\beta \sigma_{E}}{\sigma_{N}} \log \left(\operatorname{Pr}\left(l \mid n^{\prime \prime}, e\right)\right)\right]^{\prime}},
$$

where we express local child opportunity values $o(n, e)$ as a function of local probabilities of remaining low-skill $\operatorname{Pr}(l \mid n, e)$ and local continuation values for low-skill adults $R(m, l)$. Amenity levels affect parents' residential choices by shifting their flow utility and continuation values $R(m, l)$. The additive shifter of flow utilities directly cancels from the residential choice. To show how a level shift of amenities affects continuation values, we first write local value functions as:

$$
\begin{array}{r}
v(m, e, k)=\log \sum_{n^{\prime} \in \mathbb{N}} \exp \left[a_{n^{\prime}}^{e}+\frac{1}{\sigma_{N}} I_{n^{\prime}}^{e k}-c_{m m^{\prime}}^{e k}\right. \\
+1_{k=1} \beta \sum_{k^{\prime}} \operatorname{Pr}\left(k^{\prime} \mid l\right) v\left(m^{\prime}, l, k^{\prime}\right) \\
\left.-1_{k=1} \frac{\beta \sigma_{E}}{\sigma_{N}} \log \left(\operatorname{Pr}\left(l \mid n^{\prime}, e\right)\right)\right],
\end{array}
$$

where we again express local child opportunity values $o(n, e)$ as a function of local continuation values for low-skill adults and local probabilities of remaining low-skill. We now guess and verify that shifting amenity levels by a factor $b^{e}$ will shift value functions additively by a factor $B^{e k}$. In particular, we show that $\tilde{v}(m, e, k)=B^{e k}+v(m, e, k)$, where we define $\tilde{v}(m, e, k)$ to be the value function that corresponds to the shifted amenity values $a_{n}^{e}+b^{e}$. For non-parents, this is trivial to show since amenities only affect flow utility so that:

$$
\tilde{v}(m, e, 0)=B^{e 0}+v(m, e, 0)=\log \sum_{n^{\prime} \in \mathbb{N}} \exp \left[b^{e}+a_{n^{\prime}}^{e}+\frac{1}{\sigma_{N}} I_{n^{\prime}}^{e 0}-c_{m m^{\prime}}^{e 0}\right],
$$

where our guess holds if $B^{e 0}=b^{e}$. For parents, amenity levels affect flow utility and 
continuation values so that we apply our guess on both sides of the equation:

$$
\begin{aligned}
\tilde{v}(m, e, 1)=\log \sum_{n^{\prime} \in \mathbb{N}} \exp \left[b^{e}+a_{n^{\prime}}^{e}+\frac{1}{\sigma_{N}} I_{n^{\prime}}^{e 1}-c_{m m^{\prime}}^{e 1}\right. & +\beta \sum_{k^{\prime}} \operatorname{Pr}\left(k^{\prime} \mid l\right)\left(B^{l k^{\prime}}+v\left(m^{\prime}, l, k^{\prime}\right)\right) \\
& \left.\quad-\frac{\beta \sigma_{E}}{\sigma_{N}} \log \left(\operatorname{Pr}\left(l \mid n^{\prime}, e\right)\right)\right] \\
= & b^{e}+\beta \sum_{k^{\prime}} \operatorname{Pr}\left(k^{\prime} \mid l\right) B^{l k^{\prime}}+v(m, e, 1) .
\end{aligned}
$$

Our guess holds if:

$$
B^{e 1}=b^{e}+\beta\left[\operatorname{Pr}(k=0 \mid l) b^{l}+\operatorname{Pr}(k=1 \mid l) B^{l 1}\right],
$$

where we use our result that $B^{e 0}=b^{e}$ for non-parents. Rearranging this equation allows us to solve for the additive shifters of value functions. For low-skill parents, the shifter is:

$$
B^{l 1}=\frac{b^{l}(1+\beta \operatorname{Pr}(k=0 \mid l))}{1-\beta \operatorname{Pr}(k=1 \mid l)}
$$

and for high-skill parents:

$$
B^{h 1}=b^{h}+\frac{\beta b^{l}(1+\operatorname{Pr}(k=0 \mid l))}{1-\beta} .
$$

We have now shown that a shift in amenity levels also shifts value function levels additively. These additive shifters therefore cancel from parents' residential choice probabilities (cf. Equation OA.18). Parents' residential choices are therefore invariant to the normalization of amenity levels conditional on education choices.

Last, we have to show that children's education choices are also invariant to changes in amenity levels. Local education choices are given by:

$$
\sigma_{E} \log \left(\frac{\operatorname{Pr}(h \mid n, e)}{\operatorname{Pr}(l \mid n, e)}\right)=R(m, h)-R(m, l)+\mathcal{K}_{n}^{e}+\gamma^{e} \log \left(f_{n}\right),
$$

where $\mathcal{K}_{n}^{e}$ is exogenous education quality, $f_{n}$ is school funding, and $R(m, h)-R(m, l)$ are returns to education. Returns to education are given by the difference in continuation values for low- and high-skill adults, where $R(m, e)$ is the expected continuation value of young adults of education $e$ before knowing their fertility shock which is defined as: $R(m, e) \equiv \sum_{k} \operatorname{Pr}(k \mid e) V(m, e, k)$. Recall that we infer the exogenous education quality $\mathcal{K}_{n}^{e}$ as a structural residual from Equation OA.19 to fit observed education choices.

We have shown above that a shift in amenity levels by $b^{e}$ shifts value function levels by $B^{e k}$, which shifts education returns additively by: $\sum_{k} \operatorname{Pr}(k \mid h) B^{h k}-\sum_{k} \operatorname{Pr}(k \mid l) B^{l k}$. To fit observed education outcomes, our model offsets the shift in education returns by inversely adjusting the level of exogenous local education quality $\mathcal{K}_{n}^{e}$ (cf. Equation OA.19). The level of skill-specific amenities $a_{n}^{e}$ and the level of exogenous education quality $\mathcal{K}_{n}^{e}$ are 
therefore jointly, but not separately, identified. We have shown that the normalization of amenities for each skill type is without loss of generality because all model outcomes are invariant to the normalization.

Identifying Amenity and Education Quality Levels. In the implementation of our estimation strategy, we infer amenities $a_{n}^{e}$ as a structural residual from non-parents' countyutilities. We normalize these amenities to have mean zero across all neighborhoods within each education type. We then use value function iteration to solve for the value functions $v(m, e, k)$ that are consistent with these amenity levels. Last, we use Equation OA.19 and the value function estimates to infer the exogenous component of education quality $\mathcal{K}_{n}^{e}$ as a structural residual that fits observed education choices.

\section{C.5 Transitional Dynamics and Persistence in Regional Characteristics}

We hold regional characteristics constant in our counterfactual analysis. To test this assumption, we investigate how much characteristics are changing over the decades that we observe in the data. We use the structure of the model to infer regional characteristics for 1990, 2000, and 2010 and compute their correlations across decades. We restrict the sample to workers who are older than 25 years, which is the only age restriction we can implement in all three decades. Table OA.4 shows that total factor productivity and skill intensities in CZs are very persistent, with correlations between 0.81 and 0.93 across decades and correlations above 0.89 for consecutive decades. Likewise, countylevel housing supply strongly correlates over time with correlations above 0.94 across all three decades. County amenities for low-skill families have a correlation of 0.73 between 1990 and 2000 and 0.92 between 2000 and 2010. Amenities for high-skill families are more persistent, with correlations of 0.92 and 0.94 for consecutive decades. Moving costs are also very persistent, with correlations of 0.99 across decades for each education and family type. We can infer the exogenous component of local education quality only for one cross-section due to data constraints. As a result, we cannot test its persistence over time. Our results indicate that regional characteristics are very persistent between 1990 and 2010, justifying our approach of holding them constant in our counterfactuals.

\section{C.6 Relationship between Amenity Estimates and Observable Charac- teristics}

We test the extent to which our model-implied amenity estimates correlate with observable proxies of local amenities. We obtain data on local amenities from Diamond (2016) 


\begin{tabular}{lccc}
\hline & \multicolumn{3}{c}{ Correlation Between Estimates From } \\
\cline { 2 - 4 } Regional Characteristic & $1990 \& 2000$ & $2000 \& 2010$ & $1990 \& 2010$ \\
\hline Productivity $\left(\hat{\mathcal{Z}}_{m}\right)$ & 0.97 & 0.95 & 0.87 \\
Skill Intensity $\left(\hat{\mathcal{S}}_{m}^{e}\right)$ & 0.89 & 0.93 & 0.81 \\
Housing Supply $\left(\hat{\mathcal{H}}_{n}\right)$ & 0.97 & 0.96 & 0.94 \\
Low-Skill Amenity $\left(\hat{a}_{n}^{l}\right)$ & 0.73 & 0.92 & 0.81 \\
High-Skill Amenity $\left(\hat{a}_{n}^{h}\right)$ & 0.92 & 0.95 & 0.81 \\
\hline
\end{tabular}

Notes: This table shows the correlation between regional characteristics estimated from data in 1990, 2000, and 2010.

and Lee and Lin (2018) and extend their data sets over time and to the county level when possible. Table OA.5 shows the results from regressing our model-inferred amenities on these measures of observable amenities at the county level. For 2010, we find that the regressions have strong explanatory power with R-squared values of 0.8 for low- and highskill families. For 1990 and 2000, we find somewhat lower R-squared values, ranging from 0.52 to 0.77 across different education samples. We infer amenities from residential choices and do not target any observable regional characteristics. The strong relationship between our model-implied amenities and observed proxies is therefore reassuring. 
TAble OA.5: Correlation Between Model Amenity Estimates And Observable CHARACTERISTICS

\begin{tabular}{|c|c|c|c|c|c|c|}
\hline \multirow[b]{3}{*}{ Variable } & \multicolumn{6}{|c|}{ Amenity Estimates by Year and Skill Group } \\
\hline & \multicolumn{2}{|c|}{1990} & \multicolumn{2}{|c|}{2000} & \multicolumn{2}{|c|}{2010} \\
\hline & Low & High & Low & High & Low & High \\
\hline Moderate Temperature & $\begin{array}{c}0.562^{* * *} \\
(0.121)\end{array}$ & $\begin{array}{c}0.188^{* *} \\
(0.0912)\end{array}$ & $\begin{array}{l}0.144^{*} \\
(0.0805)\end{array}$ & $\begin{array}{l}0.133^{*} \\
(0.0730)\end{array}$ & $\begin{array}{r}-0.0458 \\
(0.0605)\end{array}$ & $\begin{array}{c}-0.171^{* *} \\
(0.0745)\end{array}$ \\
\hline Distance City D2 & $\begin{array}{c}-0.445^{* * *} \\
(0.118)\end{array}$ & $\begin{array}{c}-0.448^{* * *} \\
(0.0888)\end{array}$ & $\begin{array}{c}-0.467^{* * *} \\
(0.0835)\end{array}$ & $\begin{array}{c}-0.480^{* * *} \\
(0.0758)\end{array}$ & $\begin{array}{c}-0.477^{* * *} \\
(0.0604)\end{array}$ & $\begin{array}{c}-0.653^{* * *} \\
(0.0744)\end{array}$ \\
\hline Distance City D3 & $\begin{array}{c}-0.583^{* * *} \\
(0.141)\end{array}$ & $\begin{array}{c}-0.559 * * * \\
(0.106)\end{array}$ & $\begin{array}{c}-0.807^{* * *} \\
(0.101)\end{array}$ & $\begin{array}{c}-0.735^{* * *} \\
(0.0920)\end{array}$ & $\begin{array}{c}-0.742^{* * *} \\
(0.0792)\end{array}$ & $\begin{array}{c}-0.982^{* * *} \\
(0.0975)\end{array}$ \\
\hline Distance Lake D2 & $\begin{array}{c}-0.00926 \\
(0.101)\end{array}$ & $\begin{array}{c}-0.00360 \\
(0.0758)\end{array}$ & $\begin{array}{r}-0.0807 \\
(0.0698)\end{array}$ & $\begin{array}{r}-0.0896 \\
(0.0633)\end{array}$ & $\begin{array}{c}-0.0968^{*} \\
(0.0554)\end{array}$ & $\begin{array}{c}-0.129 * \\
(0.0682)\end{array}$ \\
\hline Distance Lake D3 & $\begin{array}{c}0.00532 \\
(0.121)\end{array}$ & $\begin{array}{l}0.0244 \\
(0.0910)\end{array}$ & $\begin{array}{r}-0.0680 \\
(0.0839)\end{array}$ & $\begin{array}{r}-0.0678 \\
(0.0762)\end{array}$ & $\begin{array}{r}-0.0968 \\
(0.0666)\end{array}$ & $\begin{array}{r}-0.0995 \\
(0.0821)\end{array}$ \\
\hline Distance Shore D2 & $\begin{array}{r}0.0807 \\
(0.105)\end{array}$ & $\begin{array}{r}-0.0251 \\
(0.0786)\end{array}$ & $\begin{array}{c}0.115 \\
(0.0746)\end{array}$ & $\begin{array}{l}0.0611 \\
(0.0677)\end{array}$ & $\begin{array}{r}-0.0189 \\
(0.0618)\end{array}$ & $\begin{array}{r}-0.0496 \\
(0.0762)\end{array}$ \\
\hline Distance Shore D3 & $\begin{array}{c}-0.0743 \\
(0.136)\end{array}$ & $\begin{array}{r}0.0865 \\
(0.102)\end{array}$ & $\begin{array}{l}0.153^{*} \\
(0.0915)\end{array}$ & $\begin{array}{l}0.140^{*} \\
(0.0830)\end{array}$ & $\begin{array}{r}-0.0151 \\
(0.0745)\end{array}$ & $\begin{array}{l}0.0536 \\
(0.0918)\end{array}$ \\
\hline Establishments & $\begin{array}{c}0.526^{* * *} \\
(0.0705)\end{array}$ & $\begin{array}{c}0.816^{* * *} \\
(0.0529)\end{array}$ & $\begin{array}{c}0.651^{* * *} \\
(0.0540)\end{array}$ & $\begin{array}{c}0.721^{* * *} \\
(0.0490)\end{array}$ & $\begin{array}{c}0.681^{* * *} \\
(0.0241)\end{array}$ & $\begin{array}{c}0.818^{* * *} \\
(0.0297)\end{array}$ \\
\hline Property Crime Rate & $\begin{array}{c}0.308^{* * *} \\
(0.0684)\end{array}$ & $\begin{array}{c}0.252^{* * *} \\
(0.0514)\end{array}$ & $\begin{array}{c}0.162^{* * *} \\
(0.0221)\end{array}$ & $\begin{array}{c}0.110^{* * *} \\
(0.0201)\end{array}$ & $\begin{array}{c}1.012^{* * *} \\
(0.105)\end{array}$ & $\begin{array}{c}0.968^{* * *} \\
(0.129)\end{array}$ \\
\hline Violent Crime Rate & $\begin{array}{c}-0.116^{* * *} \\
(0.0416)\end{array}$ & $\begin{array}{c}-0.196^{* * *} \\
(0.0313)\end{array}$ & $\begin{array}{c}-0.0613^{* * *} \\
(0.0178)\end{array}$ & $\begin{array}{c}-0.140 * * * \\
(0.0162)\end{array}$ & $\begin{array}{c}-0.147^{* *} \\
(0.0711)\end{array}$ & $\begin{array}{c}-0.328^{* * *} \\
(0.0875)\end{array}$ \\
\hline Park Expenditure & $\begin{array}{c}0.138^{* * *} \\
(0.0514)\end{array}$ & $\begin{array}{c}0.0701^{*} \\
(0.0386)\end{array}$ & $\begin{array}{r}-0.0192 \\
(0.0371) \\
\end{array}$ & $\begin{array}{c}0.139 * * * \\
(0.0337)\end{array}$ & $\begin{array}{c}-0.0313^{* *} \\
(0.0154)\end{array}$ & $\begin{array}{r}-0.0125 \\
(0.0190) \\
\end{array}$ \\
\hline Observations & 723 & 723 & 801 & 801 & 571 & 571 \\
\hline R-Squared & 0.520 & 0.748 & 0.599 & 0.772 & 0.794 & 0.800 \\
\hline
\end{tabular}

Notes: We use our model to infer county amenities by skill group for 1990, 2000, and 2010. We restrict the data to population above 25 years. Moderate temperature is a dummy that is equal to 1 if the minimum temperature during January lies between -5 and 15 degrees and the maximum temperature during July lies between 15 and 32 degrees. Distances from the city center, lakes, or shores enter each as three dummy variables indicating whether a distance lies in the bottom quartile (D1), the second or third quartile (D2), or the top quartile (D3) of distances observed in the sample. The omitted category is the shortest distance dummy (D1). Temperature and distance variables are obtained from Lee and Lin (2018) and mapped to the county level. Total number of establishments is constructed at the county level from the County Business Patterns. Government expenditure for parks and recreational activities is obtained from the county-area files of the Census of Governments. Property and violent crime rates are obtained from Diamond (2016) at the MSA level and expressed per 100,000 inhabitants. 